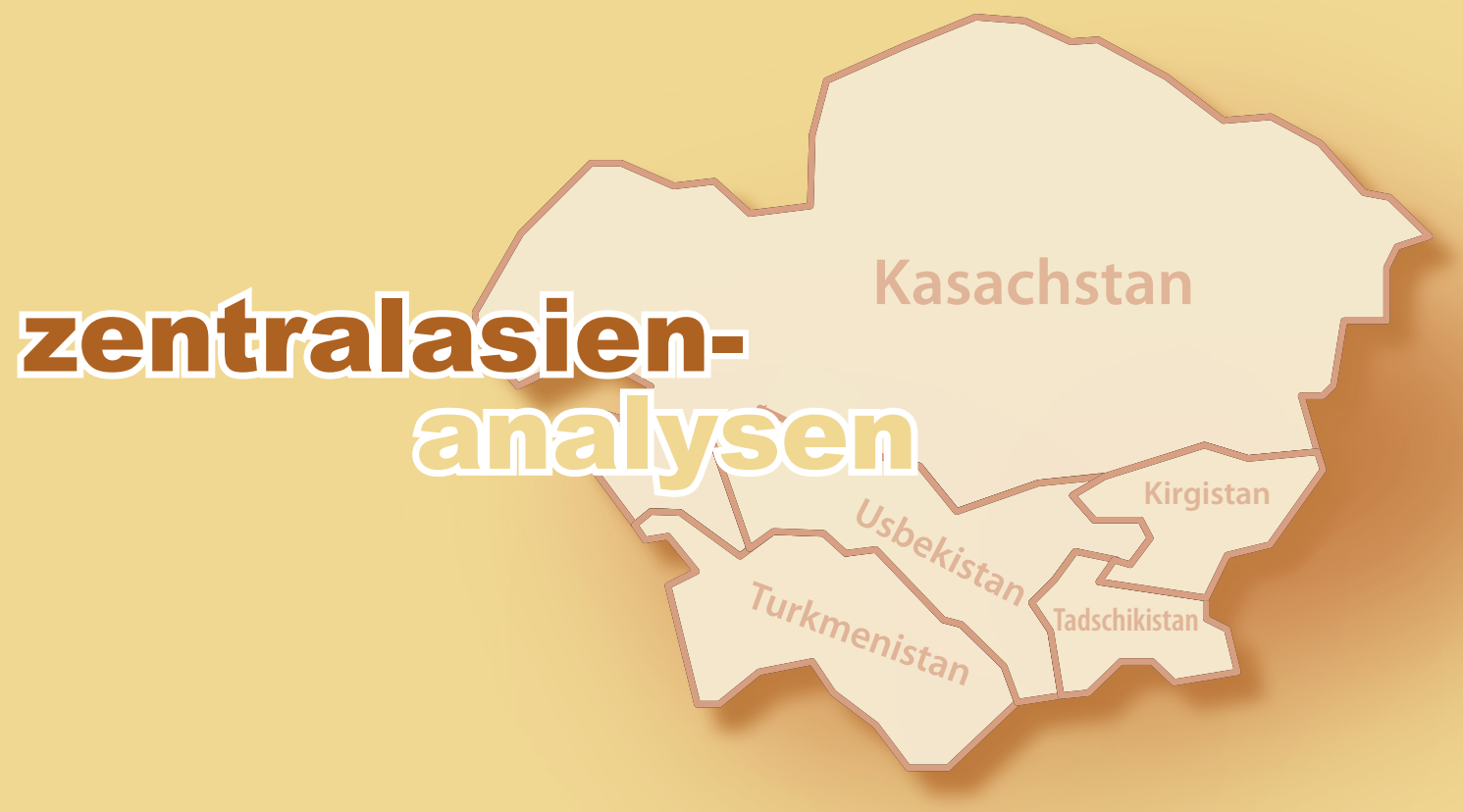

\title{
ANALYSE
}

Polizeireform in Kirgistan: Mechanismen der Gemeindesicherheit als Schritt zum

fundamentalen Wandel?

Von Philipp Lottholz, Birmingham

Materialien und Daten zur Polizeireform in Kirgistan

DOKUMENTATION

Kein Meilenstein, sondern wieder ein Etappensieg. Parlamentswahlen in Kasachstan

CHRONIK

20. Februar - 25. März 2016

Kasachstan

Kirgistan

Tadschikistan

Turkmenistan

Usbekistan 


\section{Polizeireform in Kirgistan: Mechanismen der Gemeindesicherheit als Schritt zum fundamentalen Wandel?}

Von Philipp Lottholz, Birmingham

\section{Zusammenfassung}

Der folgende Beitrag erörtert die jüngsten Entwicklungen bei der Reformierung der Polizei in Kirgistan. Als Teil des Rahmenkonzepts der Sicherheitssektoren-Reform (Security Sector Reform) ist diese ein mehr oder weniger integraler Bestandteil der Transformationsprozesse in Zentralasien. Der unterschiedliche Grad an Kooperationsbereitschaft in Demokratisierungs- und Reformfragen und spezifische nationale politische Entwicklungspfade in den zentralasiatischen Republiken kristallisieren sich allerdings auch im Bereich der Reform von Polizei und Rechtspflegeorganen heraus. Die Einbindung zivilgesellschaftlicher Organisationen in dieses Feld ist in Kirgistan zwar vergleichsweise groß, doch der Reformprozess ist weiterhin ein zähes Unterfangen, in dem die Regierung und das Innenministerium um die Sicherung der Kontrolle sowie die Begrenzung der Geschwindigkeit und der Reichweite der Reformen bemüht sind. Die folgende Analyse ist auf die Aktivitäten der Bürgervereinigung »Für Reformen und ein Ergebnis« und anderer internationaler Akteure fokussiert. Im Mittelpunkt der Darstellung stehen Versuche, transparentere und partizipatorische Reformpraktiken einzuführen, um Prozesse nachvollziehbarer für die Bürger zu gestalten und deren Beziehung zu Rechtspflegeorganen nachhaltig zu verändern. Neben Erfolgen und Einschränkungen dieser Initiativen werden auch das Potenzial und die Herausforderungen der Arbeit in partizipatorischen Community Security (dt. Gemeindesicherheits)-Projekten diskutiert.

\section{Vergangene Entwicklungen und neue Initiativen}

Reformen der Polizei, der Strafverfolgungsorgane bzw. des Sicherheitssektors als solchem gelten als wichtiger Bestandteil von demokratischem Wandel und als Basis einer nachhaltigen gesellschaftlichen Entwicklung. Ungeachtet der sehr unterschiedlichen Bereitschaft zur Kooperation und Orientierung an Prinzipien der Demokratisierung und des sozialen Wandels haben die verschiedenen zentralasiatischen Staaten das Thema Polizeireform jedoch zum Feld der Behauptung ihrer Souveränität und Kontrolle über innere Angelegenheiten gemacht. Sie haben sich entsprechend entweder ganz gegen eine Kooperation entschieden oder die Geschwindigkeit und Reichweite der Angleichung nationaler Strukturen mit von Gebern und internationalen Organisationen angebotenen Ordnungskonzepten beschränkt. So kann auch die Polizeireform in Kirgistan als Bereich gesehen werden, in dem die bisherigen Regierungen des Landes nur bedingt Kooperationsbereitschaft zeigten oder zumindest keine substanziellen Maßnahmen zur Umsetzung ihrer Ankündigungen und Pläne ergriffen. Dieser Widerstand gegen den Reformdruck mag vor allem vor dem Hintergrund zweier Revolutionen im Lande im vergangenen Jahrzehnt verständlich sein, insbesondere angesichts des Ausmaßes der Gewalt in der Aprilrevolution 2010 und bei den Unruhen im Süden des Landes im Juni desselben Jahres. Bei politischen Entscheidungsträgern scheint die Besorgnis zu bestehen, dass der Reformprozess durch eine zu offene Debatte über Funktionsmechanismen, interne Strukturen und Organisationsprinzipien der Polizei von nationalen oder externen Nicht-Regierungsakteuren »übernommen« werden könnte. Dies könnte im Umkehrschluss zum Umbau der Strukturen für innere Sicherheit führen, der den Zugriff und die Kontrolle seitens der Regierungsakteure sowie die effektive Umsetzung von Politiken hemmen könnte. Prinzipien wie die strikte Kommandohierarchie, interne Rechenschaftspflicht und die Vertraulichkeit interner Informationen und Strukturen scheinen den Entscheidungsträgern zu wichtig zu sein, als dass sie diesbezüglich Zugeständnisse machen könnten. Die Reformbestrebungen seitens der Regierung und des Innenministeriums waren somit auf die Erhöhung der Leistungsfähigkeit und Modernisierung der materiellen Basis der Polizeieinheiten beschränkt. Ein konstruktiver Dialog mit der Bevölkerung und die Zusammenarbeit mit derselben zur nachhaltigen Kriminalitäts- und Gewaltprävention bzw. -bekämpfung sind indes laut Angaben mehrerer Beobachter ausgeblieben.

Zivilgesellschaftliche Akteure, vor allem zahlreiche Menschenrechtsorganisationen, waren dagegen sehr bemüht größere Fortschritte in den Polizeireformprogrammen, die sich bereits seit dem Jahr 1998 hinzogen, zu bewirken. Es liegt im Interesse dieser Akteure wie auch der Bevölkerung, dass die Polizei gewissenhaft ihren Auftrag erfüllt und dass sich die Beamten dabei an das Gesetz halten. Die alltäglichen Erfahrungen vieler Kirgisen widersprechen diesem Idealzustand: Kor- 
ruption - z. B. in Form von Bestechungsgeldforderungen von Verkehrspolizisten - oder die Vernachlässigung von Dienstpflichten durch Beamte, die Anzeigen nicht aufnehmen und keine Ermittlungen einleiten, sind für viele Menschen eher der Normalfall als die Ausnahme. Die harsche Kritik an den Polizeikräften, zum Beispiel aufgrund von Menschenrechtsverletzungen im Nachgang zu den »Osch-Ereignissen«, wird durch die Vertreter des Innenministeriums und die Regierung generell zurückgewiesen. Die Zivilgesellschaft hat sich angesichts dieser Probleme weitgehend auf die Identifizierung von Verfahrensfehlern und Menschenrechtsverletzungen sowie deren Korrektur mittels öffentlicher Kampagnen oder auf dem Rechtsweg konzentriert. Es gibt jedoch keine Hinweise, dass sich nichtstaatliche Akteure um die Ausarbeitung konkreter institutioneller Veränderungsmaßnahmen bemüht hätten, welche die Arbeit der Polizei verbessern könnten.

Die Arbeit der Bürgerallianz "Für Reformen und ein Ergebnis» (Graschdanskij Sojus »Za reformy i resultat «) ist in diesem Zusammenhang einzigartig, da sie es geschafft hat, sich aktiv an der Diskussion, Planung und Umsetzung der Polizeireform in Kirgistan zu beteiligen. Das Netzwerk von 28 Nicht-Regierungsorganisationen (NGOs) wurde zum ersten Mal im Jahre 2013 zu Beratungen mit nationalen Entscheidungsträgern eingeladen und hat in der Folge sowohl auf nationaler Ebene versucht, Veränderungen zu erwirken, als auch in ausgewählten Ortschaften in ganz Kirgistan partizipatorische sog. Community Security (dt. Gemeindesicherheits)-Ansätze in die Praxis umgesetzt.

\section{Wandel in der Rhetorik, nicht in der Praxis}

Mitbestimmung in der nationalen Politik war anfangs das Hauptziel der Aktivisten der Bürgerallianz »Für Reformen und ein Ergebnis« und wurde somit auf der Tagesordnung des im Juli 2012 gegründeten Netzwerkes als wichtigstes Thema definiert. Mitgliedsorganisationen hatten vor der Gründung bereits mehr als 30 öffentliche Anhörungen in der ganzen Republik veranstaltet und auf deren Basis ein "Alternatives Konzept für die Reform der Strafverfolgungsorgane« erarbeitet, welches die wichtigsten Versäumnisse und Unzulänglichkeiten im Reformansatz des Innenministeriums thematisierte und Verbesserungsvorschläge machte. Der erste Erfolg des neu etablierten Aktivistennetzwerkes war die Sammlung von 10.950 Unterschriften zur Unterstützung einer Petition, die das Parlament und die Regierung aufforderte, ihr "Alternatives Konzept« als Basis für die Polizeireform in Betracht zu ziehen. Die breite allgemeine Unterstützung der Initiative der Bürgerallianz bewirkte, dass ausgewählte Aktivisten bald zu Beratungen mit offiziellen staatlichen Vertretern bis hin zum damaligen Premierminister Dschantoro Satybaldijew eingeladen wurden, der bei einem Treffen im Februar 2013 ihre Forderungen zu berücksichtigen versprach.

Diese Einbindung der Bürgerallianz in den Reformprozess kann als großer Erfolg gewertet werden, vor allem angesichts der Übernahme einiger ihrer Vorschläge in den Regierungsbeschluss Nr. 220 vom 30. April 2013, der die Bildung eines Koordinierungsrates bei der Regierung vorsieht, in dem Vertreter der Behörden sowie der Zivilgesellschaft und internationaler Organisationen den Fortschritt der Reformen bewerten und weitere Maßnahmen diskutieren sollten. Es muss aber auch konstatiert werden, dass der Umgang zwischen Aktivisten und Regierungsvertretern nicht nur konstruktiv war. Dies mag u. a. am scharfen Ton der Petitionen und öffentlichen Aussagen der Allianz gelegen haben, in denen immer wieder eine kritische Haltung gegenüber den Versäumnissen der Behörden ausgedrückt wurde. Ein weiterer den Einfluss der Bürgerallianz limitierender Faktor war der Generationsunterschied zwischen den zumeist in der Sowjetunion ausgebildeten und praxiserprobten Strafverfolgungsexperten und den "jungen Leuten", deren Interesse an Themen wie Sicherheit und Rechtspflege als bestenfalls ungewöhnlich, potenziell gar als verdächtig angesehen wird.

Zwar wurde versucht, diese Unterschiede in der sozialen Zusammensetzung und "Mentalität« durch die Einbindung ehemaliger Mitarbeiter der Strafverfolgungsorgane in die Bürgerallianz auszugleichen, diese und andere Maßnahmen konnten aber den offensichtlichen Mangel an konkreten Reformtätigkeiten in den folgenden Monaten und Jahren nicht verändern. Es wurden zwei weitere Regierungsbeschlüsse verabschiedet, die eine normativ-gesetzliche Grundlage für die »komplexe Bewertung der Tätigkeit der Strafverfolgungsorgane» (24. Februar 2015) und für die engere Zusammenarbeit der Strafverfolgungsorgane mit der Zivilgesellschaft (30. Juli 2015) bildeten. Die Beschlüsse stellen inhaltlich einen Meilenstein in der Gestaltung der Beziehungen zwischen Polizei und Bevölkerung dar. Ihre Umsetzung in konkrete Maßnahmen erwies sich jedoch als langwieriger Prozess, der teilweise auf Widerstand der Mitarbeiter der Behörden stieß. Der Koordinierungsrat konnte sich nicht bewähren, insofern er - über die Funktion einer Dialogplattform hinaus - kein Mandat hatte, konkrete Maßnahmen anzuordnen. Angesichts des stillen Widerstands seitens der Behörden und der insgesamt unbefriedigenden Umsetzung der neu konzipierten Polizeireform entschied sich die Bürgerallianz für eine teilweise Neuorientierung ihrer Tätigkeit in den Kommunen. Dies hatte den Zweck, mehr aktive Mitglieder anzuwerben und weiteres Potenzial zu bilden und zu konsolidieren, und war auf die praktische Anwendung 
partizipatorischer Community Security-Praktiken ausgerichtet, welche die Allianz auf der nationalen Ebene als wichtige Neuerung beworben hatte.

\section{Gemeindesicherheits-Praktiken als Ausdruck institutionellen Wandels?}

Durch ihre ersten Erfahrungen mit partizipatorischen Techniken während der Erhebung und Ausformulierung einer öffentlichen Meinung im Rahmen der Versammlungen im Jahre 2011 (Entwicklung des alternativen Konzepts; s.o.) war die Bürgerallianz »Für Reformen und ein Ergebnis« gut auf die eigenständige Realisierung der gesetzlich verordneten Zusammenarbeit zwischen Strafverfolgungsorganen und Bevölkerung bei der Planung örtlicher Sicherheit und der Bewertung der Tätigkeit der Polizei vorbereitet. Das größte Vorhaben dieser Art wurde durch das Büro für Drogen- und Verbrechensbekämpfung der Vereinten Nationen (UNODC) unterstützt. Im Rahmen dieser Kooperation wurden in 12 Kommunen, verteilt über alle sieben Gebiete Kirgistans, so genannte kommunale Arbeitsgruppen gebildet, die im Rahmen von regelmäßigen Arbeitstreffen die lokale Sicherheitssituation analysierten, Prioritäten definierten und auf dieser Basis kommunale Sicherheitspläne entwarfen. Mitglieder in diesen von den örtlichen Behörden beauftragten Arbeitsgruppen waren neben Vertretern der örtlichen Verwaltung und der Zivilgesellschaft auch die zuständigen Polizisten.

Das Projekt war vor allem in den Kommunen erfolgreich, in denen die Bürgerallianz bereits eine Unterstützerbasis in Form von NGOs oder einzelnen Aktivisten hatte. Hier war die Teilnahme während der Arbeitsgruppentreffen hoch; Diskussionen wurden offen und kontrovers geführt, wodurch fundierte Entscheidungen zu verschiedenen Sachverhalten getroffen werden konnten. Eine geringe Beteiligung an Arbeitsgruppentreffen und Motivationsmangel bei der Umsetzung der verschiedenen Projektkomponenten waren andernorts zwar zu beobachten, blieben aber eine Ausnahme.

Ein ernst zu nehmendes Problem des partizipatorischen Ansatzes ist das oft zu beobachtende stark vereinfachte Verständnis von Problemzusammenhängen und entsprechenden Lösungsansätzen bei sichtlich nicht ausreichender Beratung mit verschiedenen betroffenen Gruppen. Zum Beispiel planten einige Arbeitsgruppen Maßnahmen, um die Anfälligkeit junger Leute für Kriminalität und soziale Probleme zu vermindern, ohne nach deren Bedarfen und Ideen zu fragen. In einem anderen Fall diskutierte eine Gruppe die Eindämmung von Aktivitäten auswärtiger religiöser Missionare. Die Gruppe sah sich machtlos, da effektive gesetzliche Instrumente und Zwangsmaßnahmen in diesem Fall begrenzt bzw. nicht vorhanden waren, und schien die
Möglichkeit langfristiger und "weicher" Maßnahmen nicht ernsthaft in Erwägung zu ziehen. Außerdem zeigte sich, dass viele in den Gruppen diskutierte Sicherheitsprobleme eng mit den sozio-ökonomischen Verhältnissen und der Armut im Land im Zusammenhang standen bzw. gänzlich in diesem Problemfeld anzusiedeln waren und nicht im Sicherheitsbereich. Zum Beispiel erörterten manche Gruppen die unzureichende und weiter verfallende Infrastruktur oder die Problematik des Diebstahls von Nutztieren. In diesen Fällen erwiesen sich die Arbeitsgruppen aber als nützliche Plattform um Probleme zu diskutieren und sie gegenüber der lokalen bzw. Stadtverwaltung, aber auch zum Beispiel der regionalen Verwaltung für innere Angelegenheiten, zur Sprache zu bringen.

Der wohl wichtigste Aspekt dieser Zusammenarbeit auf kommunaler Ebene war jedoch der Signaleffekt der Interaktion zwischen Strafverfolgungsorganen und der Bevölkerung, bzw. lokaler Verwaltung und Zivilgesellschaft. Ein solches Zusammenspiel war in den 12 ausgewählten Kommunen eine seltene, wenn nicht einmalige Gelegenheit und wies auf die Bereitschaft der Beamten hin, der Bevölkerung zuzuhören und sich vor ihr zu verantworten. Wie oben erwähnt schien eine Generalüberholung des Polizeiapparates bis auf das kommunale Niveau angesichts des Widerstandes gegenüber konkreter Reformmaßnahmen auf nationaler Ebene nur in sehr langfristiger Perspektive möglich, wenn überhaupt. In der Zwischenzeit verwirklichte die Bürgerallianz »Für Reformen und ein Ergebnis« die Maßnahmen zur kooperativen Herstellung der Gemeindesicherheit immerhin mit sofortiger Wirkung. Diese Priorisierung der Sicherheit von Kommunen und ihrer Einwohner - zumindest in den 12 für das Projekt ausgewählten Orten - reflektiert im weiteren Sinne den Ansatz der menschlichen Sicherheit (engl. human security), der menschlichen Bedürfnissen und dem alltäglichen Leben mehr Beachtung zugesteht als institutionellen Strukturen und nationalen Sicherheitsimperativen. Die gesetzliche Verordnung und praktische Umsetzung von Gemeindesicherheitsmechanismen wird von vielen Experten als Zeichen eines fundamentalen Umdenkens seitens der Behörden gewertet.

\section{Die Wahrnehmung der Polizei in der Bevölkerung verändern}

Eine der aktivsten Organisationen im Bereich der Polizeireform in Kirgistan ist die in Großbritannien registrierte internationale NGO »Saferworld", die großen Wert auf die Unterstützung ihrer Maßnahmen durch die Regierung und die Ministerien legt und an der nachhaltigen Förderung von Frieden und nachhaltiger sozialer Entwicklung arbeitet. Eine ihrer wichtigsten Aktivitä- 
ten ist zugleich auch am wenigsten sichtbar: die Erhöhung des Kapazität kirgisischer NGOs (inklusive der Bürgerallianz), sich an Debatten zur nationalen Politik bzw. der Mitsprache an Entscheidungen in Bischkek zu beteiligen. Diese Art von Unterstützung wird in der Form von kontinuierlicher Kommunikation und Beratung geleistet - Aktivitäten, die nicht immer auf Projektbasis finanziert werden können und somit umso wertvoller sind.

$\mathrm{Zu}$ den nach außen hin sichtbaren Aktivitäten gehört die Unterstützung des Projektes "Meine Polizei beschützt mich«. Unter diesem Titel organisierte eine NGO im Süden des Landes die Produktion eines Dokumentarfilms über die Polizei; eine Fotoausstellung und einen Malwettbewerb zum Thema und die Gestaltung von Street Art-Graffitis, die Polizeibeamte im freundlichen Umgang mit jungen Menschen darstellen. Diese Idee wurde weiterhin in einer Aktion für ein positives Image der Polizei verwendet, im Rahmen derer Plakate aufgehängt wurden, die den Alltag der Interaktion zwischen Bürgern verschiedenen Hintergrunds und Polizeibeamten zeigen und mit Untertiteln wie »Wenn ich groß bin, will ich Polizist werden« oder »Wir sind immer bereit zu helfen« beschreiben. Neben diesen Initiativen, die, ob bewusst oder unbewusst, offensichtlich die Beziehung der Bevölkerung zur Polizei verändern werden, stellt Saferworld auch die Anerkennung der Bemühungen auf Seiten der Zivilgesellschaft und seitens der Polizeibeamten und Behörden sicher. Die Verleihung von Ehrenurkunden, Geschenken und Preisen an die Partner im Rahmen festlicher Veranstaltungen wie der jüngsten Preisverleihung für die »Beste Initiative von Frauen und Jugendlichen« im Februar 2016 erhöht deren Motivation sich nachhaltig zu engagieren und trägt zum Aufbau eines Netzwerkes von Gleichgesinnten in staatlichen Institutionen und der Zivilgesellschaft bei.

Ein weiterer Protagonist in der Polizeireform ist das Büro für Drogen- und Verbrechensbekämpfung der Vereinten Nationen (UNODC), das ähnliche Ziele verfolgt, aufgrund seiner größeren finanziellen Möglichkeiten aber auch die materielle Komponente und Fragen der Potenzialerhöhung abdecken kann, welche von den kirgisischen Entscheidungsträgern oft als Grund für unzureichende oder weitgehend ausbleibende Reformen angeführt werden. Dementsprechend hat UNODC Polizeipersonal ausgebildet und, wie die Bürgerallianz und Saferworld, die Sicherheitslage in ausgewählten Kommunen analysiert und in Zusammenarbeit mit der Polizei und Lokalverwaltungen Sicherheitspläne ausgearbeitet, aber auch bei der Renovierung oder beim Neubau von Polizeiwachen in verschiedenen Ortschaften finanzielle Unterstützung geleistet. Die Organisation für Sicherheit und Zusammenarbeit in Europa (OSZE) arbeitet ebenfalls im Bereich der Polizeireform und hat hierfür ein langfristiges Projekt unter dem Titel Community Security Initiative, in welchem Polizei, lokale Verwaltung und Bevölkerung an dem Ziel arbeiten, »den Respekt für Menschenrechte seitens der Polizei zu stärken und Beziehungen zur Gesellschaft in den Kommunen aufzubauen«. Es gibt jedoch auch Stimmen, denen zufolge die OSZE und die zahlreichen ehemaligen Polizeibeamten in ihren Reihen sich generell mehr auf Potenzialerhöhung fokussieren und sich während der Debatten im Koordinierungsrat tendenziell den Standpunkten der Regierung und des Innenministeriums anschließen.

\section{Fazit und Ausblick}

Aus all dem kann geschlossen werden, dass die Polizeireform in Kirgistan nicht mehr in den Bahnen des alten modus operandi verläuft. Die Gründung der Bürgerallianz »Für Reformen und ein Ergebnis« und ihr »Alternatives Konzept für die Polizeireform « hat bereits jetzt bedeutende Veränderungen bewirkt. Die Regierung hat in Person der aufeinander folgenden Premierminister wie von Vertretern des Innenministeriums die Notwendigkeit für einen komplexeren und inklusiven Ansatz bei der Reformierung der Polizei anerkannt, wie auch ihrer Bewertung und der zukünftigen Bewahrung der Sicherheit auf kommunalem Niveau. In der Folge hat sich bisher vor allem die Rhetorik geändert und es wurde eine normativ-legislative Basis gebildet, die das Innenministerium und die Strafverfolgungsorgane dazu anhält, komplexe Bewertungsmethoden anzuwenden und die Zusammenarbeit mit der Zivilgesellschaft zu stärken. Eine wahrnehmbare Umsetzung der verordneten Maßnahmen ist bisher jedoch noch nicht erfolgt.

Aus diesem Grund hat sich die Bürgerallianz inzwischen mehr auf die Umsetzung partizipatorischer Ansätze auf der kommunalen Ebene konzentriert, was, wie oben ausgeführt zur Schaffung eines Umfeldes geführt hat, in dem menschliche Sicherheit gestärkt bzw. überhaupt hergestellt wird, indem die Rechenschaftspflicht der Polizei und deren kooperative Zusammenarbeit mit lokalen Behörden und der Bevölkerung im Rahmen der kommunalen Arbeitsgruppen sichergestellt wird.

Eine Veränderung der Wahrnehmung der Polizei ist angesichts der umfangreichen Bemühungen der Bürgerallianz, von Saferworld und anderen Akteuren wahrscheinlich nur eine Frage der Zeit. Es bleibt abzuwarten, inwiefern sich die Arbeitsweise der Polizei im Rahmen dieses Imagewechsels tatsächlich wandelt. Hierbei wird wahrscheinlich die Rolle progressiv denkender Polizeibeamter und Mitarbeiter des Innenministeriums in ihren eigenen Institutionen entscheidend sein und wie erfolgreich nationale und internationale NGOs ihre Zusam- 
menarbeit mit diesen Akteuren nutzen und ausbauen können. Es ist vorstellbar, dass die kirgisische Polizei sich zu einer transparenten und modernen Institution hin wandelt, wie sie sich viele in Hinblick auf das westliche Vorbild wünschen. Die gesetzliche Einführung von Gemeindesicherheitsmechanismen, also der Zusammenarbeit zwischen Polizei, Zivilgesellschaft, Verwaltung und Bevölkerung in der Kriminalitäts- und Gewalt- prävention und -bekämpfung, wird allgemein als großer Schritt in Richtung eines fundamentalen Wandels gewertet. $\mathrm{Ob}$ diese Entwicklung jedoch weitere Veränderung im Rechts- und Strafverfolgungssystem Kirgistans bewirkt oder diese aufgrund erhöhter Anpassungsfähigkeit einzelner Kommunen abdingbar macht, bleibt abzuwarten.

\section{Über den Autor:}

Philipp Lottholz ist Doktorand am International Development Department (IDD), University of Birmingham. Im Rahmen seiner Feldforschung begleitete er im Jahr 2015 mehrere Gemeindesicherheits- und Friedensbildungsinitiativen in Kirgistan. Seine Forschungsinteressen sind Friedens- und Konfliktforschung, Internationale Politische Ökonomie und politische Soziologie.

\section{Lesetipps:}

- Erica Marat, OSCE Police Reform Programmes in Kyrgyzstan and Tajikistan: Past Constraints and Future Opportunities, EUCAM Policy Brief No. 27, Oct. 2012, = <http:/www.eucentralasia.eu/uploads/tx_icticontent/EUCAMPB-27-EN-OSCE-Police-Reform.pdf>

- Kornely Kakachia, Liam O'Shea, Why does police reform appear to have been more successful in Georgia than in Kyrgyzstan or Russia?, in: PIPSS (The Journal of Power Institutions in Post-Soviet Societies) 13(2012), = < http:// pipss.revues.org/3964>

- Lisa Denney, Securing communities? Redefining community policing to achieve results, Overseas Development Institute Report, March 2015, = <http://www.odi.org/sites/odi.org.uk/files/odi-assets/publications-opinionfiles/9582.pdf>

- Dieter Bricke, Das Human Security-Konzept, in: Wissenschaft \& Frieden, 2003/2, = <http://www.wissenschaftund-frieden.de/seite.php?artikelID=0246>

\section{Materialien und Daten zur Polizeireform in Kirgistan}

\section{Ausgewählte Ergebnisse einer Meinungsumfrage über Wahrnehmung und Bewertung der Polizei}

Grafik 1: Wahrnehmung der Polizei (2015, in \% der Befragten)

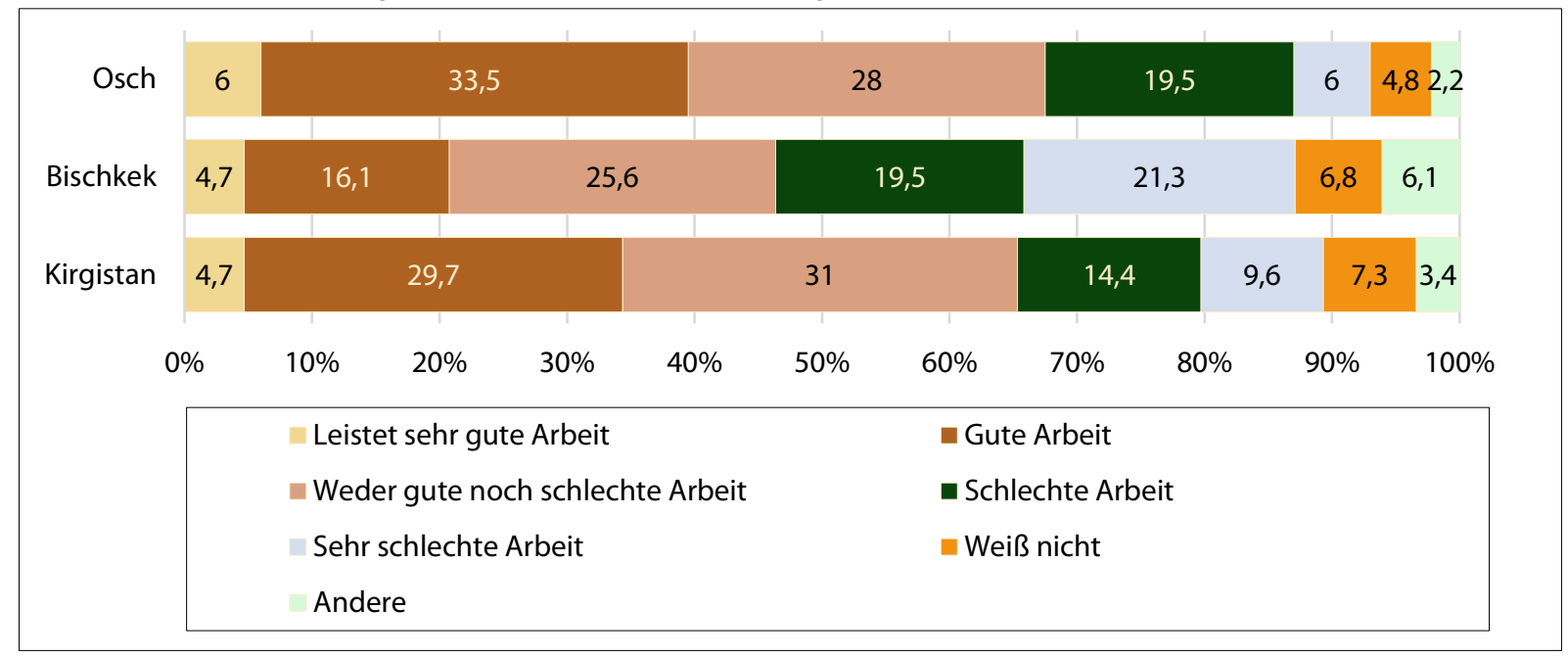

Quelle: Kyrgyzstan Public Safety Survey 2015; <http://www.reforma.kg/sites/default/files/icvs_report_eng.pdf> 
Grafik 2: Häufigkeit der Sichtung von Polizeistreifen zu Fuß? (\% der Befragten)

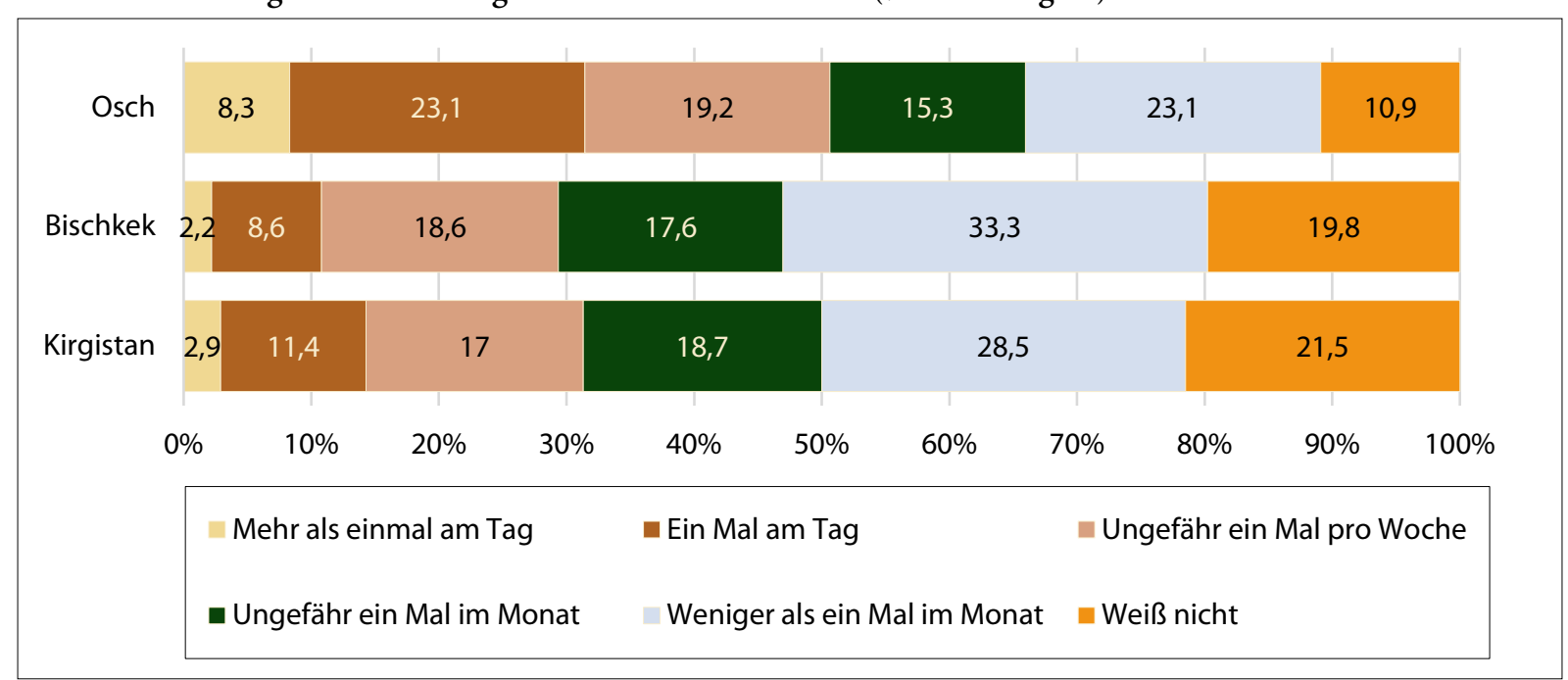

Quelle: Kyrgyzstan Public Safety Survey 2015; <http://www.reforma.kg/sites/default/files/icvs_report_eng.pdf>

Grafik 3: Selbstinitiierter Kontakt zur Polizei in den letzten zwölf Monaten (in \% der Befragten)

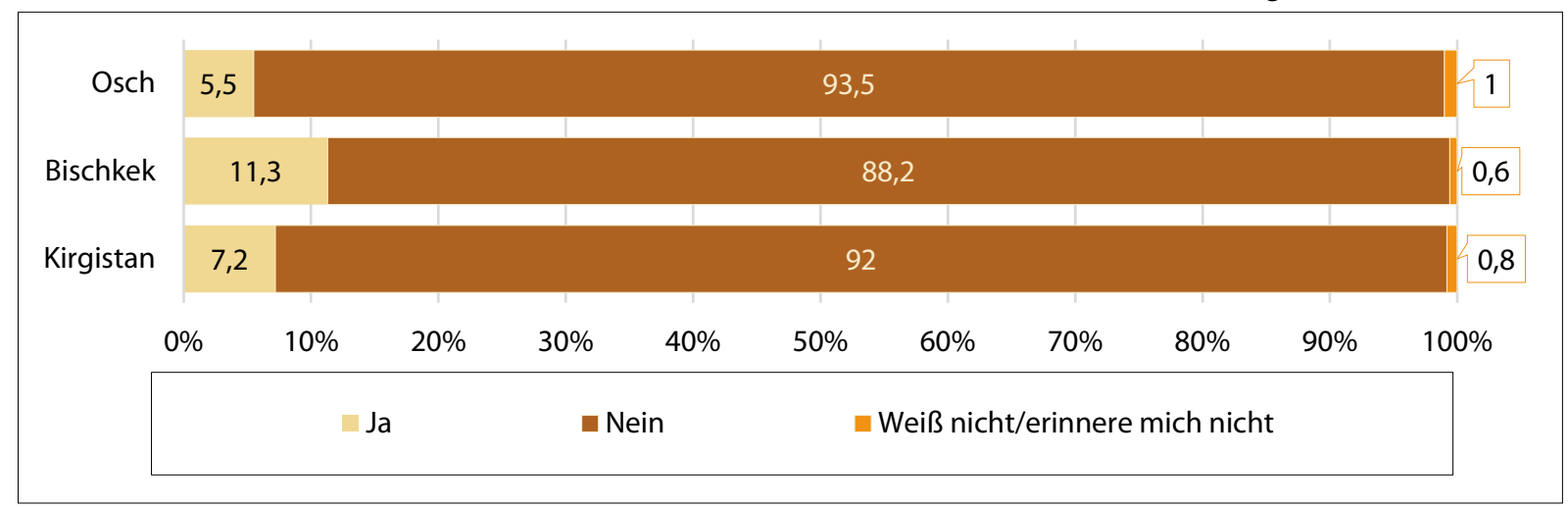

Quelle: Kyrgyzstan Public Safety Survey 2015; <http://www.reforma.kg/sites/default/files/icvs_report_eng.pdf>

Grafik 4: Von der Verkehrspolizei angehalten in den letzten 12 Monaten (in \% der Befragten)

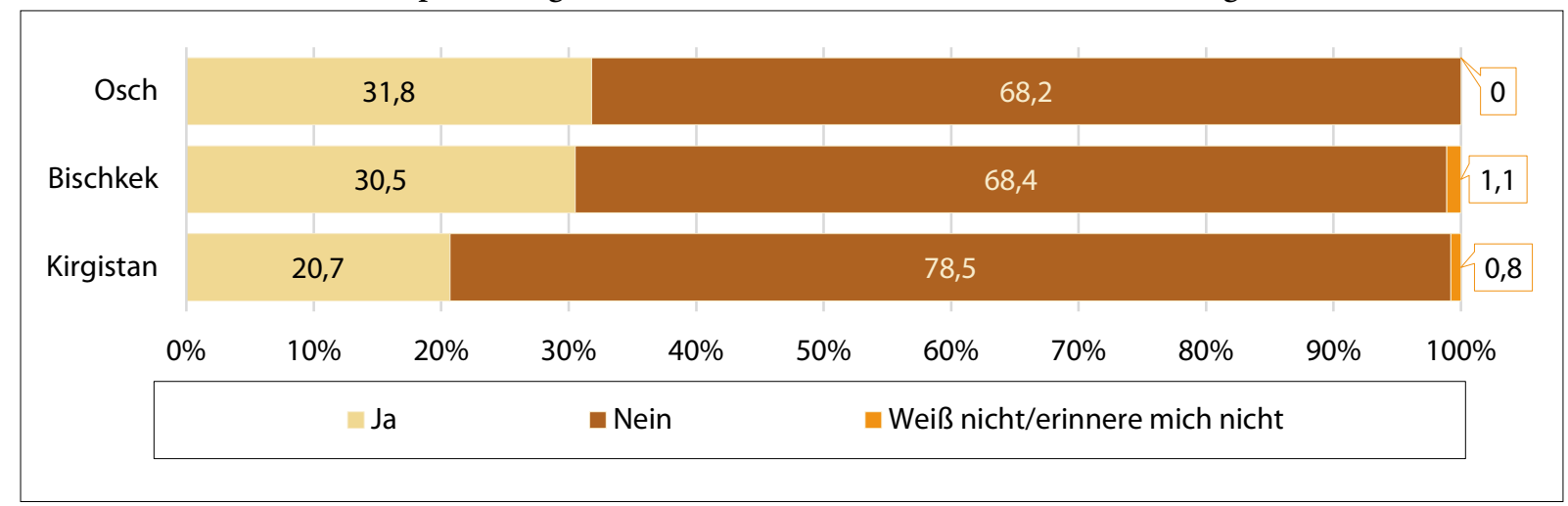

Quelle: Kyrgyzstan Public Safety Survey 2015; <http://www.reforma.kg/sites/default/files/icvs_report_eng.pdf> 
Grafik 5: Hat die Verkehrspolizei Ihnen einen Grund für das Anhalten gegeben?

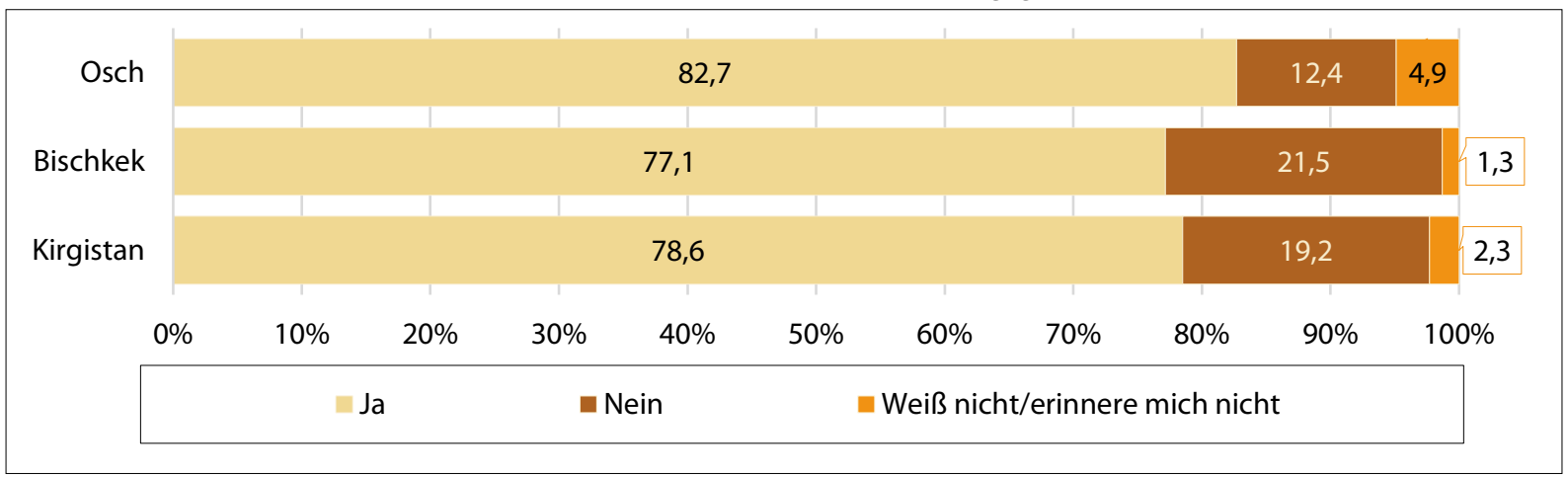

Quelle: Kyrgyzstan Public Safety Survey 2015; <http://www.reforma.kg/sites/default/files/icvs_report_eng.pdf>

\section{Grafik 6a: Einschätzung des Auftretens der Polizei (\% der landesweit in Kirgistan Befragten)}

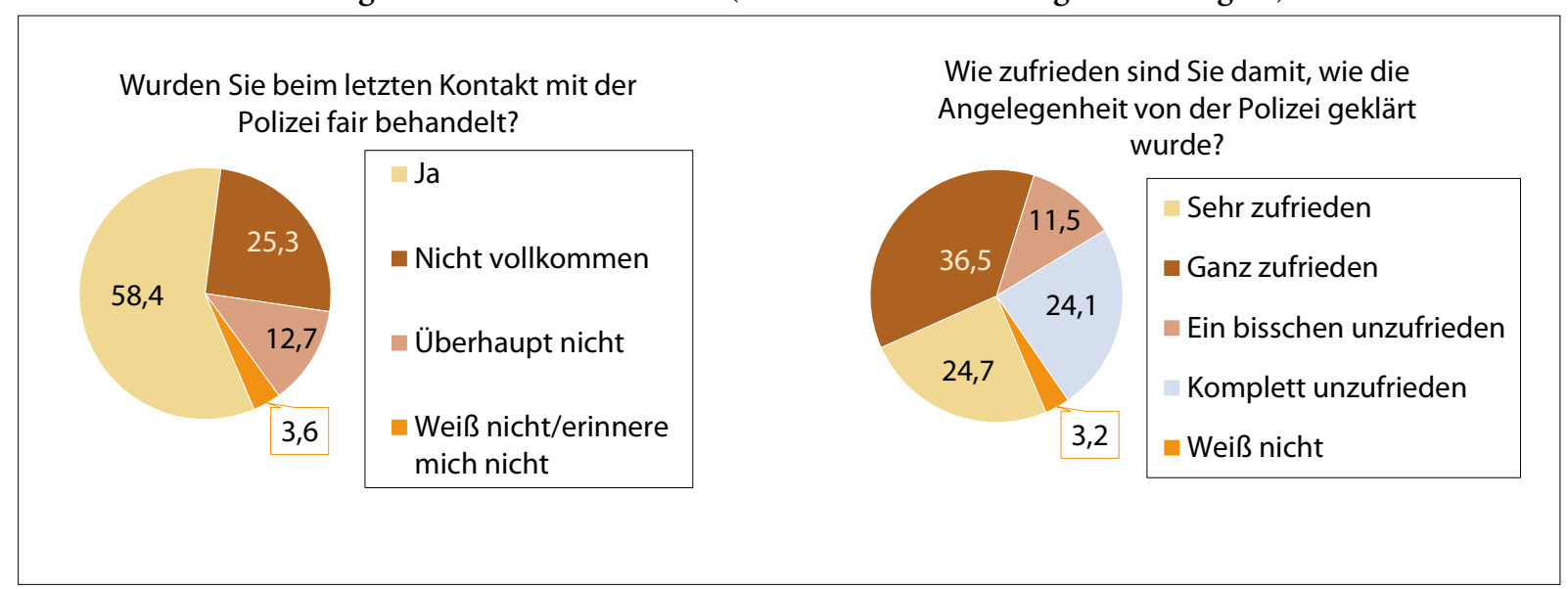

Quelle: Kyrgyzstan Public Safety Survey 2015; <http://www.reforma.kg/sites/default/files/icvs_report_eng.pdf>

Grafik 6b: Einschätzung des Auftretens der Verkehrspolizei (\% der landesweit in Kirgistan Befragten)

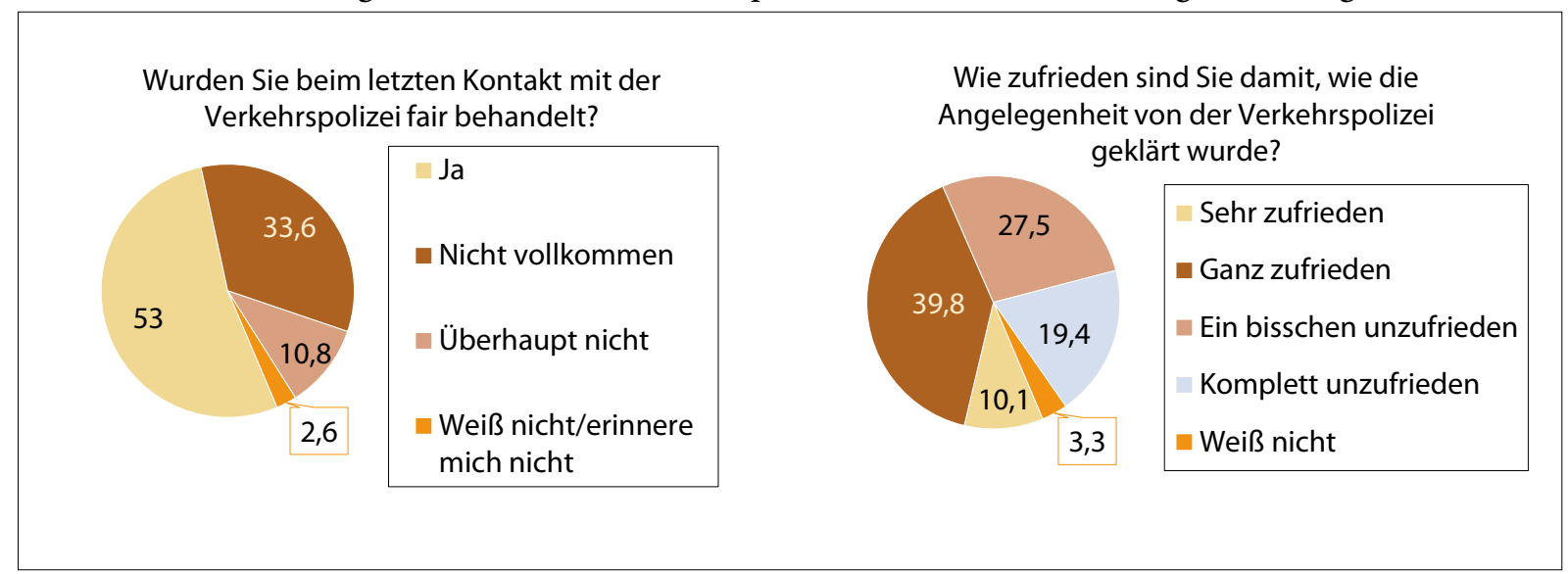

Quelle: Kyrgyzstan Public Safety Survey 2015; <http://www.reforma.kg/sites/default/files/icvs_report_eng.pdf> 
Visuelle Beispiele für die Saferworld Kampagne zur Verbesserung des Images des Polizei

Abbildung 1: Street Art-Graffiti, Projekt »Meine Polizei beschützt mich«; Osch, Dezember 2015

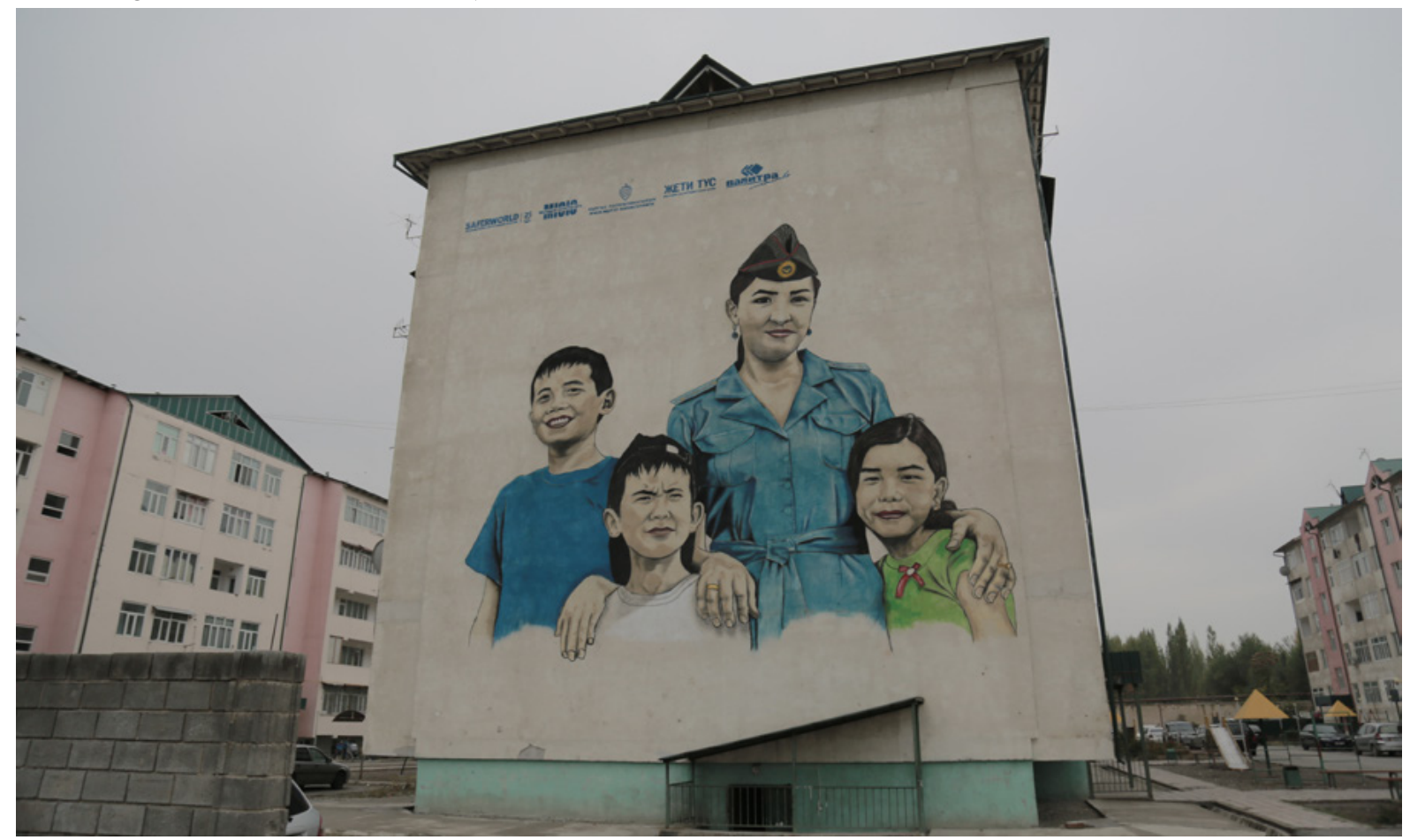

Copyright: Saferworld

Abbildung 2: "Wenn ich groß bin, will ich Polizist werden« (kirgis. Tschonnoisom milizijada itschteim), Osch, November/Dezember 2015

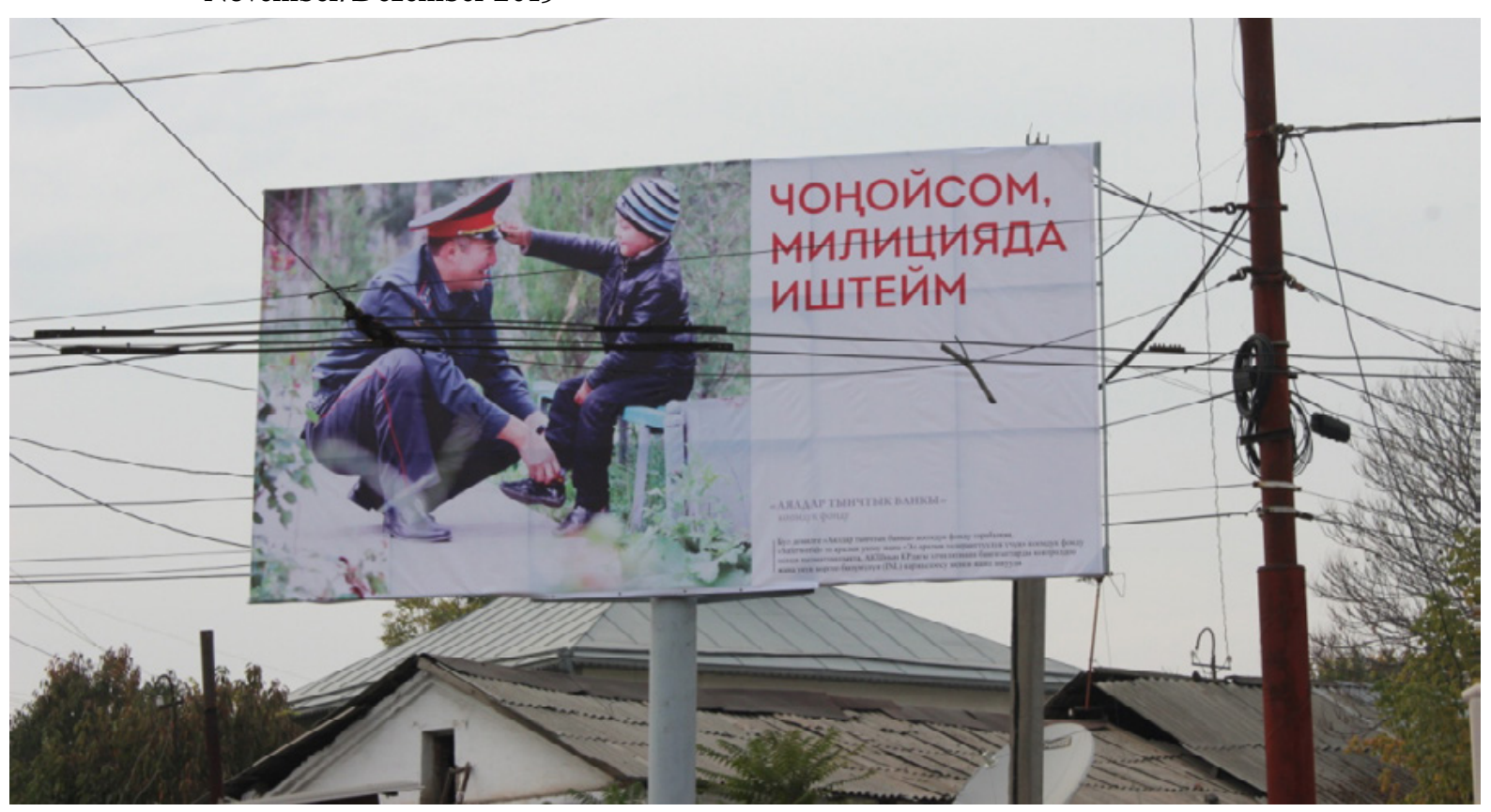

Copyright: Saferworld 
Abbildung 3: "Wir sind immer bereit zu helfen« (kirgis. Dschardamga dajym dajarbyz), Osch, November/Dezember 2015

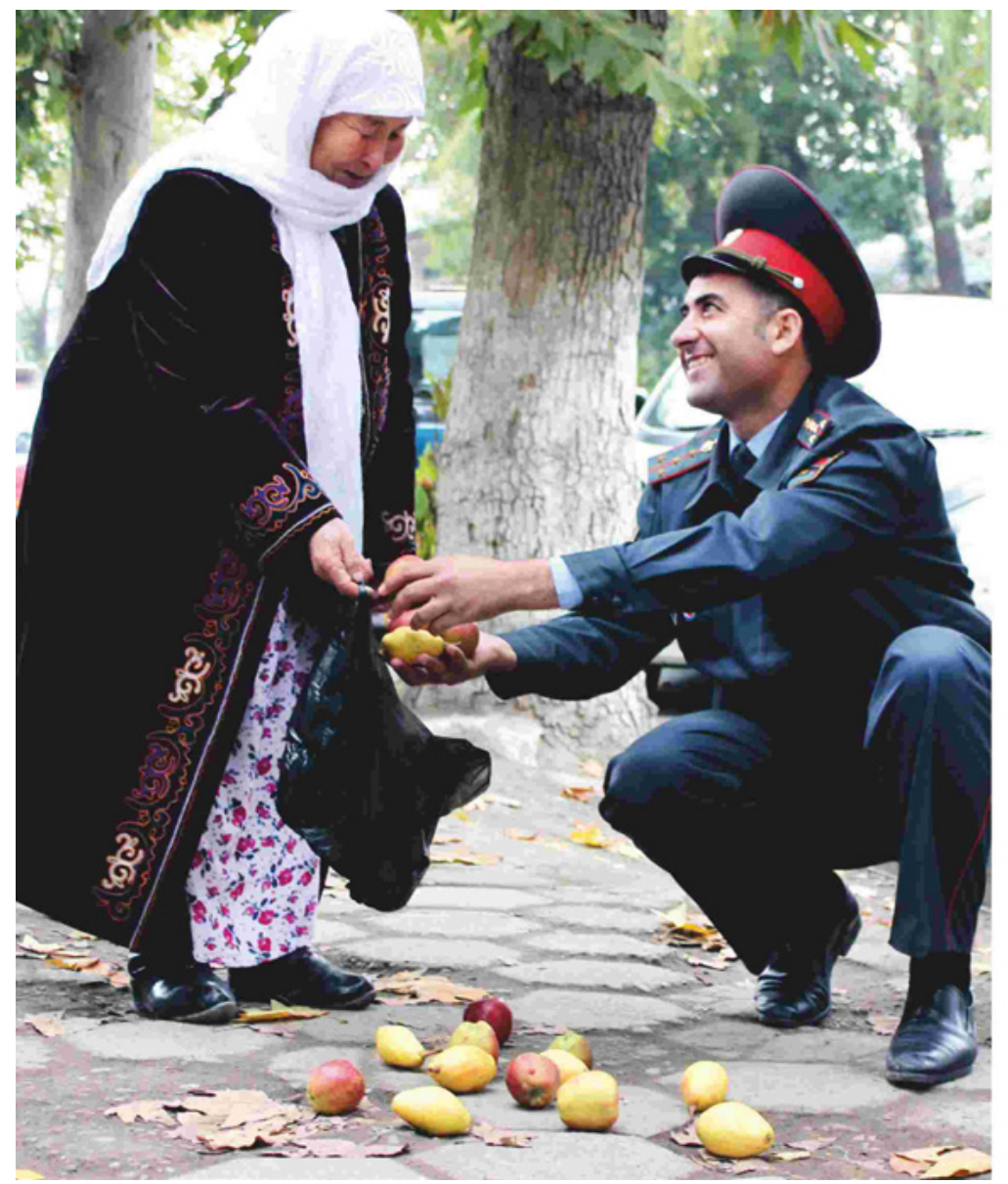

Copyright: Saferworld
ЖАРДАМГА ДАЙЫМ ДАЯРБЫЗ 


\section{Kein Meilenstein, sondern wieder ein Etappensieg. Parlamentswahlen in Kasachstan}

Am 20. März 2016 wurde in Kasachstan vorzeitig ein neues Unterhaus des Parlamentes (kas. Madschilis) gewählt. Wie von Beobachtern schon länger erwartet, hatten die Mitglieder des 2012 gewählten Unterhauses Mitte Januar den Präsidenten um Auflösung und Neuwahlen ersucht; das Parlament hat kein Recht auf Selbstauflösung. Turnmusmäßig hätte die Wahl erst im Januar 2017 angestanden. Nach Beratung mit dem Vorsitzenden des Verfassungsrates entschied der Präsident, dem Wunsch der Parlamentarier zu entsprechen und setzte die Neuwahl auf den 20. März fest. Für diesen Tag waren bereits die Wahlen für die Gebiets- und Kommunalvertretungen des Landes terminiert. Vorgezogene Wahlen sind inzwischen in Kasachstan nicht mehr eine Ausnahme, sondern eher die Regel. Die letzten drei Parlamentswahlen fanden vorgezogen statt, auch der Präsident wurde bereits mehrfach vorzeitig gewählt, zuletzt im Frühjahr 2015.

Die Vertreter der alten Madschilis hatten ihren Wunsch, von dem kritische Beobachter natürlich annehmen, dass er ihnen von oben nahegelegt wurde, mit der schwierigen Wirtschaftslage begründet, deren Lösung frische Kräfte erfordere. In der staatlich dominierten Presse wurde u. a. auch angeführt, dass man so den ausländischen Investoren mehr Planungssicherheit bieten und damit Kapitalabfluss verhindern wolle. Auch das für westliche Leser noch schwerer zu verstehende Argument, dass das alte Unterhaus den neuen geopolitischen Herausforderungen nicht gewachsen sei, tauchte auf. Tatsächlich kann man, wie schon im Frühjahr 2015 bei der vorgezogenen Präsidentenwahl davon ausgehen, dass die Wahl jetzt stattfand, weil man bei der absehbar immer schwieriger werdenden ökonomischen Lage im Laufe des Jahres 2016 einen Stimmungsumschwung in der Bevölkerung befürchtete. Außerdem will man notwendige einschneidende Maßnahmen mit dem Argument, die überwältigende Mehrheit der Bevölkerung stehe dahinter, rechtfertigen können. Daraus folgt, dass für die Führung am 20. März eine möglichst hohe Wahlbeteiligung plus natürlich ein möglichst gutes Ergebnis der Präsidentenpartei Nur Otan notwendig war.

Seit der letzten Parlamentswahl 2012 hat sich die Zahl der registrierten Parteien durch Fusionen und den Gerichtsbeschluss über die Auflösung der Kommunistischen Partei im August 2015 von zehn auf sieben verringert. Nur sechs von ihnen traten bei der Wahl an, die Partei Asat hatte sich wegen mangelnder Erfolgsaussichten von vornherein gegen eine Teilnahme entschieden. Unabhängige Kandidaten waren nicht erlaubt. Für jeden Kandidaten musste bei der notwendigen offiziellen Registrierung eine Kaution von einem Mindestlohn (ca. 850 Euro) hinterlegt werden, was für die kleinen und finanzschwachen Parteien beschränkend wirkte.

Nur in den beiden Wochen vor der Wahl war mancherorts so etwas wie ein Wahlkampf zu beobachten. Große programmatische Unterschiede zwischen den Parteien waren schon deshalb schwer möglich, als ja Parteien mit grundsätzlich anderen Ansätzen und Lösungsvorschlägen gar keine offizielle Registrierung bekommen würden. Die Themen glichen sich also und boten keine politische Alternative: Bewahrung sozialer Stabilität, Pläne für eine langfristige Bekämpfung der Wirtschaftskrise, Bewahrung der nationalen Einheit und Berufung auf nationale Werte. Die Präsidentenpartei Nur Otan dominierte das Bild. Sie verließ sich erstaunlicherweise nicht nur auf die überzeugende Wirkung ihres Zugpferdes Nursultan Nasarbajew, sondern setzte neben bekannten Politikern auch prominente und beliebte Sportler und Popstars auf ihre Liste, so den Boxer Gennadij Golowkin und den Popmusiker Kairat Nurtas.

Die 98 zu vergebenden Sitze werden nach einer landesweiten Parteiliste im Verhältniswahlrecht verteilt. Für den Einzug ins Unterhaus ist ein Ergebnis von mehr als - im internationalen Vergleich sehr hohen - $7 \%$ der abgegebenen Stimmen erforderlich. Wie erwartet wurde Nur Otan wieder stärkste Partei und erreichte mit 82,2\% ca. $1 \%$ mehr als 2012. Mit Ak Schol (7,18\%) und Volkskommunisten (7,14\%) konnten auch die beiden bisher im Unterhaus vertretenen Parteien die 7\%-Hürde überspringen. Alle anderen landeten weit abgeschlagen bei $2 \%$ und darunter. Damit ist die Verteilung der Parteien im neuen Parlament nahezu identisch mit der bisherigen: Nur Otan hat mit 84 einen Sitz mehr und Ak-Schol mit sieben einen weniger als vorher, die Volkskommunisten sind unverändert mit sieben Abgeordneten vertreten. Die Wahlbeteiligung der insgesamt 9.810 .852 Wahlberechtigen lag bei 77,12\% und damit um ca. $2 \%$ höher als bei der letzten Parlamentswahl.

Interessant sind die regionalen Unterschiede. Während landesweit zwischen 70-80\% der Wahlberechtigten teilnahmen, verweigerte sich die große Mehrheit der Bewohner der Stadt Almaty dem Wahlgang, dort gingen nur $34,1 \%$ an die Wahlurne. In der "südlichen Hauptstadt" erreichte die oppositionelle OSDP auch 9,9\% der Stimmen (in den anderen Gebieten lag ihr Anteil zwischen 0,1 und 2\%), während Nur Otan bei im Landesvergleich schwachen 70,1\% lag. In der Hauptstadt Astana erreichte die Präsidentenpartei mit 85,18\% dagegen ihr bisher bestes Ergebnis. 
Wie gewohnt bewerteten die Wahlbeobachter von GUS und SCO die Wahl positiv, während die Mission von OSZE/ODIHR, die bislang noch keine Wahl in Kasachstan als frei und fair bewertet hat, eine ganze Reihe von Kritikpunkten anmahnte (u. a. keine wirkliche politische Auswahl, Unregelmäßigkeiten bei Stimmabgabe und Auszählung, Zweifel an der Höhe der Wahlbeteiligung). In den sozialen Netzwerken tauchten diverse Videos auf, in denen Mehrfachstimmabgaben gezeigt wurden. Anders als vor einigen Jahren, als Nasarbajew der westlichen Kritik mit der Drohung, in Zukunft keine Wahlbeobachter mehr einzuladen, begegnete, reagierte man dieses Mal selbstbewusster: Kasachstan sei ein junger, noch in der Entwicklung befindlicher Staat mit anderen (asiatischen) Werten und Traditionen und werde sich zu nichts drängen lassen. Die Anwesenheit der vielen ausländischen Wahlbeobachter wurde noch stärker als früher zur Legitimierung der Wahlen verwendet. Die Staatsmedien waren voll mit Äußerungen auch westlicher Beobachter, die das hohe Niveau der Wahlen priesen („besser als in einigen europäischen Ländern...«) und vor allem die gute Stimmung und Informiertheit der Bevölkerung bestaunten. Dies wiederum veranlasste den Kommentator der fundamentaloppositionellen Internetzeitung Respublika zu der Äußerung, Wahlbeobachtung sei für Dummköpfe gedacht!

Mit der Verkündung des Wahlergebnisses war keineswegs klar, welche Personen konkret in die neue Madschilis einziehen würden. Anders als in Deutschland ist die Platzierung auf der vor der Wahl erstellten Parteiliste in Kasachstan nicht entscheidend. Erst nachdem bei der Wahl die Zahl der zu vergebenden Mandate feststeht, wird parteiintern hinter verschlossenen Türen bestimmt, wer tatsächlich ins Parlament einzieht. Auf den Listen aller drei Wahlgewinner standen mehr Namen, als sie Sitze errungen hatten - auch und vor allem betraf das Nur Otan, für insgesamt überhaupt nur 98 zu vergebende Sitze hatte man 127 Kandidaten nominiert, bei Ak-Schol waren es 35 und bei den Volkskommunisten 22. Man kann also annehmen, dass nach dem Wahlkampf für die Bevölkerung ein Machtkampf innerhalb der Parteien stattfand.

Im Ergebnis zogen bei Nur Otan (natürlich) die gelisteten prominenten Sportler und Künstler nicht ins Parlament ein, genauso wenig kandidierende bekannte ehemalige Minister oder Gouverneure, auch Präsidententochter und Vize-Premierministerin Dariga Nasarbajewa erhielt kein Mandat. Insgesamt sind ca. 60 \% der Abgeordneten Neulinge, ehemalige Staatsbedienstete und Wirtschaftsvertreter überwiegen, ihr Durchschnittsalter liegt bei 55 Jahren. (Zum Vergleich: Das Durchschnittsalter des derzeitigen Bundestages gilt mit 49,6 Jahren als hoch.) Die Versammlung des Volkes Kasachstans (ANK) wählte die ihr verfassungsmäßig zustehenden neun nicht parteigebundenen Vertreter am 21. März.

Inzwischen ist das Unterhaus am 25. März zu seiner konstituierenden Sitzung zusammen getreten und hat erwartungsgemäß Premier Karim Masimow und seine Regierung nahezu unverändert bestätigt. Einzig Energieminister Wladimir Schkolnik wurde durch den bisherigen Gouverneur von Pawlodar, Kanat Bosumbajew, ersetzt.

Ist die Wahl also, wie Präsident Nasarbajew am Wahltag erklärt hat, ein »Meilenstein« in der Geschichte Kasachstans? Hat sich etwas Entscheidendes geändert? Die Antwort ist vom Standpunkt des Urteilenden abhängig, für westliche Beobachter wie kasachstanische Oppositionelle gibt es solange keine Veränderung, wie das autokratische System unter Nasarbajew fortbesteht. Die Führung des Landes kann ihr Ziel einer möglichst hohen Bestätigung durch die Bevölkerung als erreicht betrachten. Natürlich hat keine politische Veränderung und auch keine Verjüngung, aber doch ein starker Austausch der Abgeordneten stattgefunden, die wunschgemäß aus Administration und Wirtschaft kommen. Ein Meilenstein war diese Wahl aber gewiss nicht, angesichts der schwierigen ökonomischen Lage eher wieder ein Etappensieg, wie schon die Präsidentenwahl im Vorjahr. Das öffentliche Interesse hat sich auch inzwischen, sicher u. a. von Nasarbajews Bemerkung am Wahltag angestoßen, dass es politische Veränderungen in der Verteilung der Macht geben könnte, verstärkt einem unausweichlich näher rückenden wirklichen Meilenstein zugewandt, der Frage des Machtübergangs und des möglichen Nachfolgers. 
Grafik 1: Wahlergebnis und Wahlbeteiligung der Parlamentswahlen in Kasachstan 20. März 2016

Wahlergebnis
Nur Otan
$\begin{aligned} & \text { Ak Schol } \\ & \text { Kommunistische Volkspartei } \\ & \text { Auyl } \\ & \text { OSDP } \\ & \text { Birlik }\end{aligned}$

Quelle: <http://www.election.kz/rus/news/messages/index.php?ID=3294>

Tabelle 1: Wahlergebnis und Wahlbeteiligung der Parlamentswahlen in Kasachstan 20. März 2016

\begin{tabular}{|l|r|c|}
\hline & Stimmen & $\%$ \\
\hline Nur Otan & 6.183 .757 & 82,2 \\
\hline Ak Schol & 540.406 & 7,18 \\
\hline Kommunistische Volkspartei & 537.123 & 7,14 \\
\hline Auyl & 151.285 & 2,01 \\
\hline OSDP & 88.813 & 1,18 \\
\hline Birlik & 21.484 & 0,29 \\
\hline
\end{tabular}

Wablbeteiligung: $77,12 \%$

Quelle: <http://www.election.kz/rus/news/messages/index.php?ID=3294>

Grafik 2: Sitzverteilung im Unterhaus des neuen Parlamentes

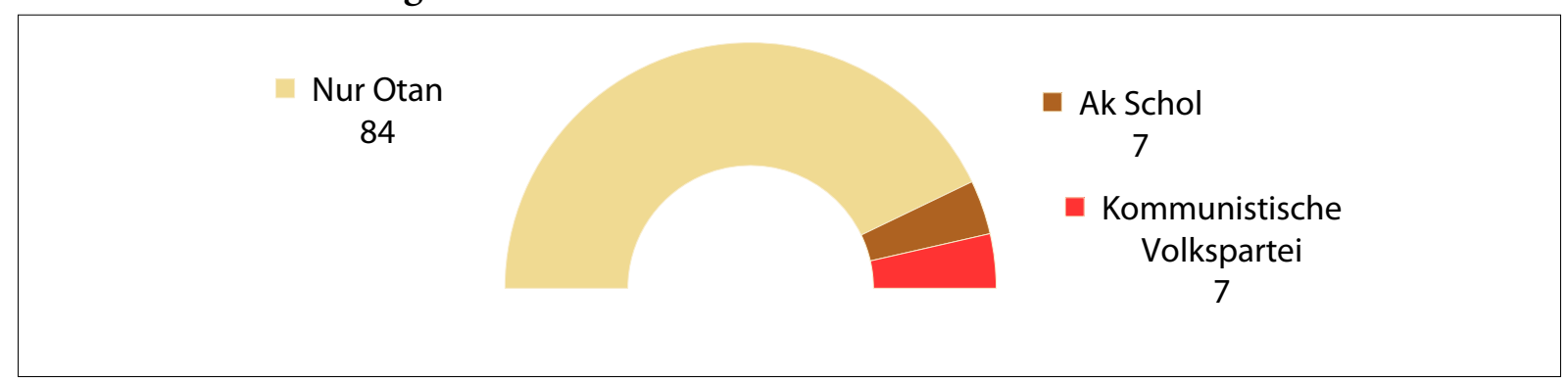

Quelle: <http://www.election.kz/rus/news/messages/index.php?ID=3294>

Grafik 3: Sitzverteilung im Unterhaus des Parlamentes 2012-2016

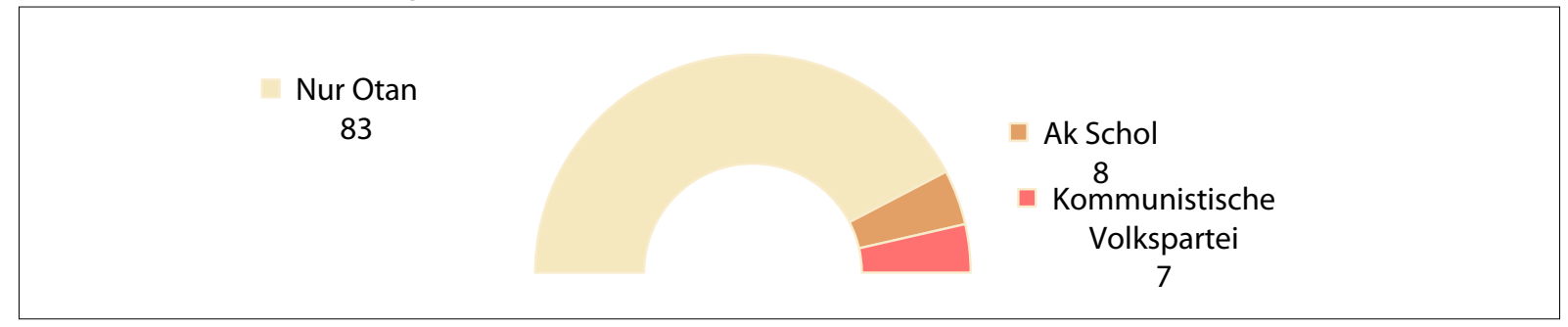

Quelle:Zentralasien-Analysen 49/2012, S.9 <http://www.laender-analysen.de/zentralasien/pdf/ZentralasienAnalysen49.pdf > ursprünglich Zentrale Wablkommission der Republik Kasachstan) 


\section{Februar - 25. März 2016}

\section{Kasachstan}

\begin{tabular}{|c|c|}
\hline 22.2 .2016 & $\begin{array}{l}\text { Der Vorsitzende des Journalistenverbandes, Seitkasy Matajew, und sein Sohn Asat, Leiter der Nachrichtenagen- } \\
\text { tur KazTAG, werden unter dem Verdacht der Veruntreuung von Haushaltsmitteln festgenommen. Das Com- } \\
\text { mittee to Protect Journalists protestiert gegen die Inhaftierung. }\end{array}$ \\
\hline 23.2 .2016 & $\begin{array}{l}\text { Silkroad Intelligencer meldet unter Berufung auf Regierungskreise, dass Kasachstan nicht von seinem Vorkauf- } \\
\text { recht für die Übernahme eines Anteils von 29,25\% am Karachaganak-Konsortiums Gebrauch machen wird, } \\
\text { das durch die Übernahme des bisherigen Anteilseigners, der britischen BG Group, durch Shell freigeworden } \\
\text { war. (Shell hat kein Anrecht auf Übernahme des von der BG Group gehaltenen Anteils.) }\end{array}$ \\
\hline 24.2 .2016 & $\begin{array}{l}\text { Der ägyptische Präsident Abdel Fattah Al-Sisi wird von Präsident Nursultan Nasarbajew in Astana zu Gesprä- } \\
\text { chen über die bilaterale Zusammenarbeit empfangen. }\end{array}$ \\
\hline 24.2 .2016 & $\begin{array}{l}\text { Die dreijährige Haftstrafe des Bürgerrechtlers Jermek Narymbajew wird durch ein Gericht in Almaty in Haus- } \\
\text { arrest umgewandelt. }\end{array}$ \\
\hline 24.2.2016 & $\begin{array}{l}\text { Der Chef des Komitees für Waldwirtschaft, Kairat Ustemirow, kündigt gegenüber Tengrinews an, dass eine } \\
\text { Fläche von insgesamt } 10.000 \text { ha in den Naturschutzgebieten des Landes für touristische Projekte privatisiert } \\
\text { werden soll. }\end{array}$ \\
\hline 25.2.2016 & $\begin{array}{l}\text { Der Generalsekretär des für die Organisation der EXPO verantwortlichen Internationalen Büros für Ausstel- } \\
\text { lungen, Vicente Loscertales, äußert bei einer Pressekonferenz in Astana sein Missfallen über das Anfang des } \\
\text { Monats im Internet aufgetauchte Schreiben des ehemaligen EXPO-2017-Beraters Juan Correas, nach dem die } \\
\text { Durchführung der Veranstaltung in Gefahr sei. }\end{array}$ \\
\hline 25.2 .2016 & $\begin{array}{l}\text { Präsident Nasarbajew empfängt den Vorsitzenden der Eurasischen Wirtschaftskommission, Tigran Sarkisian, } \\
\text { zu Gesprächen über die multilaterale Zusammenarbeit in der EEU. }\end{array}$ \\
\hline 26.2.2016 & $\begin{array}{l}\text { Einem Bericht des Analyse-Instituts Ranking.kz zufolge ist } 2015 \text { die Zahl der kasachstanischen Rentner, die } \\
\text { einer offiziellen beruflichen Tätigkeit nachgehen, um mehr als das Doppelte gestiegen. }\end{array}$ \\
\hline 26.2 .2016 & $\begin{array}{l}\text { Senatssprecher Kasym-Schomart Tokajew begrüßt in seiner Rede vor der Parlamentarischen Versammlung der } \\
\text { OSZE in Wien die Vereinbarungen zwischen USA und Russland bezüglich des Krieges in Syrien und kriti- } \\
\text { siert die Sanktionspolitik des Westens. }\end{array}$ \\
\hline 26.2.2016 & $\begin{array}{l}\text { Dem Schwager von Ex-BTA Bank-Chef Muchtar Abljasow, Syrym Schalabajew, wurde in Litauen der Flücht- } \\
\text { lingsstatus gewährt, teilt dessen Anwalt, Laimonas Judickas, mit. }\end{array}$ \\
\hline 29.2 .2016 & $\begin{array}{l}\text { Bei einem Geiseldrama im US-Bundesstaat Washington sterben auch die beiden aus Kasachstan stammen- } \\
\text { den Kinder Timur und Damir Carlson, die im Jahr } 2002 \text { aus einem Waisenhaus in Schtschutschinsk (Gebiet } \\
\text { Akmola) adoptiert worden waren. }\end{array}$ \\
\hline 29.2 .2016 & $\begin{array}{l}\text { Der vor einer Woche festgenommene Chef des Journalistenverbandes Matajew wird mit gefährlich hohem Blut- } \\
\text { druck in ein Krankenhaus gebracht. }\end{array}$ \\
\hline 1.3 .2016 & $\begin{array}{l}\text { Ein Gericht in der Stadt Almaty spricht die Journalistin Julija Koslowa vom Vorwurf des Drogenbesitzes frei. } \\
\text { Koslowa hatte auf nicht schuldig plädiert. Ihre Vorgesetzte, die Chefredakteurin des Nachrichtenportals Naka- } \\
\text { nune.kz, Gusal Baidalinowa, der geschäftsschädigende Berichterstattung gegen die Kazkommertsbank vorge- } \\
\text { worfen wird, ist nach wie vor in Haft. }\end{array}$ \\
\hline 1.3 .2016 & $\begin{array}{l}\text { Ein Gericht in Astana lehnt die Klage der Mutter eines der im Jahr } 2012 \text { am Grenzkontrollpunkt Arkankergen } \\
\text { getöteten } 14 \text { Soldaten gegen das Komitee für Nationale Sicherheit um Schadenersatz in Höhe von } 370 \text { Mio. } \\
\text { Tenge (ca. 1,1 Mio. US-Dollar) ab. Der für die Tat verantwortlich gemachte Soldat Wladislaw Tschelach wurde } \\
\text { bereits im November } 2012 \text { zu lebenslänglicher Haft wegen Massenmordes verurteilt. }\end{array}$ \\
\hline 1.3 .2016 & $\begin{array}{l}\text { Laut einer Meldung der Nationalbank ist ab sofort für den Umtausch von mehr als } 1 \text { Mio. Tenge (ca. } 2.900 \\
\text { US-Dollar) die Vorlage eines Identitätsnachweises notwendig. }\end{array}$ \\
\hline 2.3 .2016 & $\begin{array}{l}\text { Bildungsminister Takir Balykbajew kündigt bei einer Pressekonferenz an, dass das Schulfach Kasachische } \\
\text { Geschichte landesweit ab dem Jahr } 2018 \text { ausschließlich auf Kasachisch und Weltgeschichte auf Russisch unter- } \\
\text { richtet werden soll. Für Physik und Chemie soll ab dem Jahr } 2019 \text { Englisch Unterrichtssprache werden. }\end{array}$ \\
\hline 3.3 .2016 & $\begin{array}{l}\text { Der Regionaldirektor für Europa und Zentralasien von AI, John Dalhuisen, kritisiert bei der Vorstellung eines } \\
\text { Berichts zur Aufklärung von Folter in Kasachstan, dass die dortigen Behörden den Hunderten von Hinweisen } \\
\text { von Misshandlungen durch Gefängnispersonal und Polizei nicht nachgehen würden. }\end{array}$ \\
\hline
\end{tabular}




\begin{tabular}{|c|c|}
\hline 4.3.2016 & $\begin{array}{l}\text { Bei einem Runden Tisch in Almaty diskutieren Experten den Bau eines neuen Tramsystems bis zum Jahr 2020, } \\
\text { das durch die französische ALSTOM gebaut werden soll. Das alte Straßenbahnsystem wurde wegen gravieren- } \\
\text { der technischer Mängel } 2015 \text { stillgelegt. }\end{array}$ \\
\hline 4.3 .2016 & $\begin{array}{l}\text { Vier in China wegen Drogenhandels und Mord verurteilte Bürger Kasachstans werden an die kasachstanische } \\
\text { Justiz überstellt. Über die Identität der Häftlinge wird nichts bekannt. }\end{array}$ \\
\hline 5.3.2016 & $\begin{array}{l}\text { Präsident Nasarbajew unterzeichnet ein Gesetz zur Anpassung des Staatshaushalts für die Jahre 2016-18, dem } \\
\text { ein Wechselkurs des Tenge zum US-Dollar von 360:1 (statt vorher 330:1) und ein Erdölpreis von } 30 \text { (statt vor- } \\
\text { her 40) US-Dollar je Barrel zugrunde liegt. }\end{array}$ \\
\hline 8.3.2016 & $\begin{array}{l}\text { In Astana eröffnen der Bürgermeister von Astana, Adilbek Dschaksybekow, und Kulturminister Arystanbek } \\
\text { Muchamediuly offiziell die erste Filiale des Fastfood-Unternehmens MacDonald's in Zentralasien. Zuvor hatte } \\
\text { bereits Präsident Nasarbajew dem Burger-Restaurant einen Besuch abgestattet. }\end{array}$ \\
\hline 10.3 .2016 & $\begin{array}{l}\text { Der Fernsehsender KTK meldet, dass die Familie von Ex-Premier Serik Achmetow den ihm zur Last gelegten } \\
\text { Schaden von } 430 \text { Mio. Tenge (ca. 1,2 Mio. US-Dollar) an die Staatskasse zurückgezahlt hat. }\end{array}$ \\
\hline 10.3 .2016 & $\begin{array}{l}\text { Das Europäische Parlament fordert Präsident Nasarbajew in einer Stellungnahme dazu auf, die Verfolgung } \\
\text { von Journalisten einzustellen. }\end{array}$ \\
\hline 11.3.2016 & $\begin{array}{l}\text { Die kasachstanische Gewichtheberin Faina Sinanbajewa wird vom Weltverband für Schwerathletik nach mehr- } \\
\text { fachen Dopingverstößen lebenslang gesperrt. }\end{array}$ \\
\hline 11.3 .2016 & Ein französisches Gericht lehnt die Freilassung von Ex-BTA Bank-Chef Abljasow auf Kaution ab. \\
\hline 14.3.2016 & $\begin{array}{l}\text { Tengrinews meldet unter Berufung auf eine Meldung des Sozial- und Arbeitsministeriums, dass Präsident } \\
\text { Nasarbajew im Februar die Regierung zur Prüfung einer möglichen Einführung des bedingungslosen Grund- } \\
\text { einkommens in Kasachstan aufgefordert hat. }\end{array}$ \\
\hline 14.3.2016 & $\begin{array}{l}\text { Ein Gericht in Karaganda senkt die Gefängnisstrafe von Ex-Premier Achmetow von zehn auf acht Jahre. } \\
\text { Die Haftstrafe des im selben Fall verurteilten ehemaligen Gouverneurs des Gebiets Karaganda, Bauyrschan } \\
\text { Abdischew, wird von fünf auf drei verringert, die des ehemaligen Bürgermeisters der Stadt Karaganda, Mei- } \\
\text { ram Smagulow, von drei auf zwei Jahre. }\end{array}$ \\
\hline 16.3 .2016 & $\begin{array}{l}\text { Der Enkel von Präsident Nasarbajew, Nurali Nasarbajew, tritt von seinem Posten als stellvertretender Bürger- } \\
\text { meister von Astana zugunsten seiner unternehmerischen Tätigkeit zurück. }\end{array}$ \\
\hline 17.3 .2016 & $\begin{array}{l}\text { Für den Bau eines Denkmals in Astana anlässlich des 25jährigen Jubiläums der Unabhängigkeit Kasachstans } \\
\text { werden } 100 \text { Mio. Tenge (ca. } 286.000 \text { US-Dollar) aus dem Staatsbudget bereitgestellt, meldet Tengrinews. }\end{array}$ \\
\hline 18.3.2016 & $\begin{array}{l}\text { In Astana beginnt der Prozess im Fall des der Unterschlagung von Haushaltsmitteln im großen Umfang bezich- } \\
\text { tigten ehemaligen Vorstandschefs des EXPO-2017-Planungsunternehmens, Talgat Jermegijajew. }\end{array}$ \\
\hline 18.3 .2016 & $\begin{array}{l}\text { RFE/RL meldet, dass ab dem 24.3. Besucher öffentlicher Verwaltungen am Eingang ihr Handy abgeben müs- } \\
\text { sen, um den widerrechtlichen Abfluss von sensiblen internen Informationen zu unterbinden. }\end{array}$ \\
\hline 18.3.2016 & $\begin{array}{l}\text { Der Fußballclub Kairat Almaty verpflichtet den bekannten russischen Nationalspieler Andrej Arschawin für } \\
\text { zunächst ein Jahr. Sein Vertrag beim russischen Erstligisten Kuban Krasnodar hatte am 1. Februar geendet. }\end{array}$ \\
\hline 20.3 .2016 & $\begin{array}{l}\text { Im ganzen Land finden vorgezogene Wahlen für das Unterhaus des Parlamentes (Madschilis) sowie turnusmä- } \\
\text { ßige Wahlen zu den lokalen Selbstverwaltungsgremien (Maslichat) statt. }\end{array}$ \\
\hline 21.3 .2016 & $\begin{array}{l}\text { Die Zentrale Wahlkommission gibt die vorläufigen Ergebnisse der Parlamentswahlen bekannt. Danach kom- } \\
\text { men die Präsidentenpartei Nur Otan auf } 82,15 \% \text {, die Demokratische Partei Ak Schol auf 7,18\% und die Kom- } \\
\text { munistische Volkspartei auf 7,14\% der Stimmen. Alle anderen Parteien scheitern an der 7\%-Hürde. Die Wahl- } \\
\text { beteiligung lag bei } 77,1 \% \text {. }\end{array}$ \\
\hline 21.3.2016 & $\begin{array}{l}\text { Die Versammlung des Volkes Kasachstans wählt in Astana die neun Abgeordneten, die sie verfassungsgemäß } \\
\text { ins Parlament entsenden kann. }\end{array}$ \\
\hline 21.3.2016 & $\begin{array}{l}\text { PEN International ruft seine Mitglieder und Unterstützer dazu auf, sich bei der kasachstanischen Regierung } \\
\text { für die Freilassung des Dichters Aron Atabek einzusetzen. Atabek war nach den Protesten im Almatiner Vor- } \\
\text { ort Schangyrak im Jahr } 2007 \text { zu } 18 \text { Jahren Gefängnis verurteilt. Er wird für den Tod eines Polizisten während } \\
\text { der Demonstrationen verantwortlich gemacht. }\end{array}$ \\
\hline 24.3 .2016 & $\begin{array}{l}\text { Bei einer Sitzung des Führungsgremiums der Partei Nur Otan unter Leitung von Präsident Nasarbajew wer- } \\
\text { den die } 84 \text { Abgeordneten bestimmt, die die Partei laut Wahlergebnis in das neue Parlament entsenden kann. } \\
\text { Nasarbajews Tochter, Dariga Nasarbajewa, befindet sich nicht unter den Ausgewählten. }\end{array}$ \\
\hline
\end{tabular}




\begin{tabular}{|l|l|}
\hline 24.3.2016 & $\begin{array}{l}\text { Der bisherige Generaldirektor des Staatskonzerns Kazakhmys, Bachtijar Krykpyschew, wird zum neuen Auf- } \\
\text { sichtsratschef des Unternehmens bestellt. }\end{array}$ \\
\hline 25.3.2016 & Der bisherige Energieminister Wladimir Schkolnik wird durch Kanat Bosumbajew ersetzt. \\
\hline 25.3.2016 & $\begin{array}{l}\text { Auf der von Präsident Nasarbajew eröffneten konstituierenden Sitzung der neu gewählten Madschilis wird der } \\
\text { ehemalige Gouverneur des Gebiets Atyrau, Baktykoscha Ismuchambetow, zum Sprecher des Unterhauses des } \\
\text { Parlaments gewählt. }\end{array}$ \\
\hline 25.3.2016 & $\begin{array}{l}\text { Die Unterhausabgeordnete Sagipa Balijewa wird durch ein Dekret Präsident Nasarbajews zur ersten Ombuds- } \\
\text { frau für Kinderrechte bestimmt. }\end{array}$ \\
\hline
\end{tabular}

\section{Kirgistan}

\begin{tabular}{|c|c|}
\hline 21.2 .2016 & $\begin{array}{l}\text { Die seit zwei Tagen streikenden Arbeiter der Goldmine Taldy-Bulak (Gebiet Tschui) des chinesisch-kirgisi- } \\
\text { schen Joint-Ventures Altynken nehmen die Arbeit wieder auf, nachdem nach Verhandlungen mit dem Staats- } \\
\text { konzern Kyrgyzaltyn, der Gewerkschaft und staatlichen Vertretern eine ungesetzliche Lohnkürzung zurück- } \\
\text { genommen und baldige Lohnverhandlungen angekündigt wurden. }\end{array}$ \\
\hline 22.2 .2016 & $\begin{array}{l}\text { Der Journalist Turat Akimow, Herausgeber der Wochenzeitung Dengi i Wlast (Geld und Macht), auf den zwei } \\
\text { Tage zuvor ein Anschlag verübt worden war, macht Innenminister Melis Turganbajew für die Tat verantwort- } \\
\text { lich und droht im Falle eines erneuten Übergriffes die Veröffentlichung eines im Vormonat mit ihm aufge- } \\
\text { zeichneten Interviews an. Das Innenministerium weist die Vorwürfe zurück. }\end{array}$ \\
\hline 24.2.2016 & $\begin{array}{l}\text { Im Bezirk Kara-Suu (Gebiet Osch) wurde eine Frauengruppe der islamistischen Hizb ut-Tahrir aufgedeckt, } \\
\text { teilen die Sicherheitskräfte mit. }\end{array}$ \\
\hline 25.2 .2016 & $\begin{array}{l}\text { Die Stadt Osch erwirbt im Rahmen eines Finanzierungsprogrammes der EBRD vom russischen Autoherstel- } \\
\text { ler Trolza } 23 \text { neue Trolleybusse im Wert von über } 3 \text { Mio. Euro. }\end{array}$ \\
\hline 25.2 .2016 & $\begin{array}{l}\text { Nach Angaben von Premier Temir Sarijew sind die ausländischen Direktinvestitionen in den ersten neun Monaten } \\
\text { des Jahres } 2015 \text { im Vergleich zum Vorjahreszeitraum um das Anderthalbfache auf } 640 \text { Mio. US-Dollar gestiegen. }\end{array}$ \\
\hline 26.2.2016 & $\begin{array}{l}\text { Präsident Almasbek Atambajew empfängt CSTO-Generalsekretär Nikolaj Bordjuscha zu einem Gespräch } \\
\text { über die Prioritäten der weiteren Tätigkeit und die Bedrohungen durch den internationalen Extremismus und } \\
\text { Terrorismus. }\end{array}$ \\
\hline 26.2 .2016 & Mit 24 Grad Celsius wird in Bischkek die höchste Temperatur an einem Februartag seit über 50 Jahren gemessen. \\
\hline 27.2.2016 & $\begin{array}{l}\text { Das Stadtparlament von Bischkek wählt mit } 43 \text { zu } 1 \text { Stimme den einzigen Kandidaten, Albek Ibraimow, zum } \\
\text { neuen Bürgermeister. }\end{array}$ \\
\hline 29.2.2016 & $\begin{array}{l}\text { Präsident Atambajew erörtert mit dem Vorsitzenden des staatlichen Komitees für nationale Sicherheit, Abdil } \\
\text { Segisbajew, Antiterrormaßnahmen und Grundrichtungen des Kampfes gegen Extremismus und Terrorismus. }\end{array}$ \\
\hline 29.2 .2016 & $\begin{array}{l}\text { In Dschany Dscher (Gebiet Tschui) nimmt das erste Spezialgefängnis für zu lebenslänglichen Freiheitsstrafen } \\
\text { verurteilte Gefangene den Betrieb auf. }\end{array}$ \\
\hline 1.3.2016 & $\begin{array}{l}\text { Nach Angaben des Finanzministeriums lag die Staatsverschuldung Ende } 2015 \text { bei mehr als 288,8 Mrd. Som } \\
\text { (ca. } 4 \text { Mrd. US-Dollar). }\end{array}$ \\
\hline 1.3.2016 & $\begin{array}{l}\text { Vizepremierministerin Gulmira Kudaiberdijewa erörtert am Rande des Besuches einer kirgisischen Delegation } \\
\text { in New York anlässlich der 31. Sitzung des UN-Menschenrechtsrates mit UN-Generalsekretär Ban Ki-moon } \\
\text { Aktivitäten der Organisation in Kirgistan im sozialen und humanitären Bereich. }\end{array}$ \\
\hline 2.3.2016 & $\begin{array}{l}\text { Präsident Atambajew erörtert während seines Arbeitsbesuches in Moskau mit seinem russischen Amtskollegen } \\
\text { Wladimir Putin Fragen des bilateralen Verhältnisses. Ein Treffen mit dem russischen Finanzminister Anton } \\
\text { Siluanow ist ebenfalls vorgesehen. }\end{array}$ \\
\hline 3.3 .2016 & Gazprom kündigt eine Erhöhung der Gaspreise in Kirgistan an. \\
\hline 5.3.2016 & $\begin{array}{l}\text { Im dritten Stock des Gebäudes des Komitees für Staatssicherheit in Bischkek bricht aus unbekannter Ursa- } \\
\text { che ein Feuer aus. }\end{array}$ \\
\hline 9.3 .2016 & $\begin{array}{l}\text { In Moskau wird eine Gruppe von Kirgisen wegen Dokumentenfälschung verhaftet. Sie sollen Ausweispapiere } \\
\text { für Arbeitsmigranten hergestellt haben. }\end{array}$ \\
\hline 10.3 .2016 & Präsident Atambajew entlässt die Vorsitzende der Rechnungskammer, Elmira Ibraimowa, auf eigenen Wunsch. \\
\hline 10.3 .2016 & $\begin{array}{l}\text { Ulan Israilow wird neuer Direktor des Antikorruptionsdienstes des staatlichen Komitees für nationale Sicher- } \\
\text { heit. Sein Vorgänger, Bokonbaj Kasakow, hatte das Amt am Vorabend auf eigenen Wunsch aufgegeben. }\end{array}$ \\
\hline
\end{tabular}




\begin{tabular}{|c|c|}
\hline 14.3 .2016 & $\begin{array}{l}\text { Der ehemalige Bürgermeister von Bischkek, Kubanytschbek Kulmatow, wird zum neuen Vorsitzenden des Rus- } \\
\text { sisch-Kirgisischen Entwicklungsfonds ernannt. Seine Vorgängerin, Nursuluu Achmetowa, war nach Kritik an } \\
\text { ihrer Amtsführung durch Premier Sarijew von Präsident Atambajew entlassen worden. }\end{array}$ \\
\hline 16.3 .2016 & $\begin{array}{l}\text { In der Goldmine Kumtor wurden nach Firmenangaben im Jahr } 2015520.517 \text { Feinunzen bzw. knapp 16,2 t Gold } \\
\text { im Wert von 604,5 Mio. US-Dollar gefördert. Nach vorläufigen Schätzungen des Nationalen Komitees für Sta- } \\
\text { tistik trug Kumtor damit mit 6,8\% zum BIP des Landes bei und zahlte mehr als } 123 \text { Mio. US-Dollar Steuern. }\end{array}$ \\
\hline 16.3.2016 & $\begin{array}{l}\text { Präsident Atambajew empfängt den Vorsitzenden der tschechischen Abgeordnetenkammer, Jan Hamáček. Der } \\
\text { Gast äußert sein Bedauern darüber, dass es in Prag keine kirgisische Botschaft gibt. }\end{array}$ \\
\hline 17.3 .2016 & $\begin{array}{l}\text { Das Parlament verabschiedet eine Änderung des Gesetzes über onkologische Behandlung, mit der der Kreis } \\
\text { der in Spezialkliniken kostenlos Behandelten begrenzt wird. }\end{array}$ \\
\hline 18.3 .2016 & $\begin{array}{l}\text { Die Weltbank gewährt Kirgistan ein Darlehen im Umfang von } 38 \text { Mio. US-Dollar zur Erhöhung der } \\
\text { Ernährungssicherheit. }\end{array}$ \\
\hline 18.3 .2016 & $\begin{array}{l}\text { Der staatliche Dienst für den Kampf gegen Wirtschaftsverbrechen teilt mit, dass am 16.3. der wegen Betruges } \\
\text { mit internationalem Haftbefehl gesuchte Sohn des Ex-Chefs des Staatsdienstes für die Regulierung des Finanz- } \\
\text { marktes, Timur Toitschubekow, in einer Moskauer Bank verhaftet wurde. }\end{array}$ \\
\hline 18.3 .2016 & $\begin{array}{l}\text { Kirgisische Medien berichten, dass Usbekistan die letzten beiden Grenzübergänge für Kirgisen zwischen bei- } \\
\text { den Staaten geschlossen und Truppen sowie Panzerfahrzeuge an einem zwischen beiden Staaten umstrittenen } \\
\text { Grenzabschnitt im Bezirk Ala-Buka (Gebiet Dschalalabad) konzentriert habe. Kirgistan stationiert in Reak- } \\
\text { tion auch Truppen an der Grenze und sendet eine Protestnote nach Taschkent. }\end{array}$ \\
\hline 19.3.2016 & $\begin{array}{l}\text { Nach Angaben der russischen Zentralbank sind die Rücküberweisungen kirgisischer Arbeitsmigranten aus } \\
\text { Russland } 2015 \text { auf 1,083 Mrd. US-Dollar gesunken; } 2014 \text { waren es noch 2,062 Mrd. US-Dollar gewesen. }\end{array}$ \\
\hline 19.3.2016 & $\begin{array}{l}\text { Der Pressedienst des Innenministeriums meldet die Festnahme von } 369 \text { Personen und die Entdeckung von } 157 \\
\text { offiziell Vermissten im Rahmen einer Sonderaktion der GUS-Staaten am 16./17.3. }\end{array}$ \\
\hline 19.3.2016 & Ulukbek Maripow wird zum neuen Vorsitzenden der Rechnungskammer ernannt. \\
\hline 20.3 .2016 & $\begin{array}{l}\text { Tilek Alibek, einer der beiden des Angriffs auf den muslimischen Theologen Kadyr Malikow im November } \\
2015 \text { Verdächtigen, wird von der Türkei an Kirgistan ausgeliefert. Er war Ende November } 2015 \text { in Gazian- } \\
\text { tep verhaftet worden. }\end{array}$ \\
\hline 21.3.2016 & $\begin{array}{l}\text { Die russische Nachrichtenagentur TASS meldet, dass als Ergebnis von Gesprächen am 20.3. Kirgistan und } \\
\text { Usbekistan die Zahl ihrer an der Grenze konzentrierten Truppen reduziert haben. }\end{array}$ \\
\hline 22.3 .2016 & $\begin{array}{l}\text { Premier Sarijew wirbt bei einer Veranstaltung im Bezirk Ala-Buka vor ca. } 200 \text { Zuhörern für eine friedliche } \\
\text { Lösung des Grenzkonfliktes mit Usbekistan. Währenddessen wirft der Oppositionelle Asimbek Beknasarow } \\
\text { der Regierung bei einer Kundgebung mit } 700-2.000 \text { Teilnehmern in Kerben (Gebiet Dschalalabad) man- } \\
\text { gelndes Engagement bei der Lösung des Grenzproblems vor. Andere Oppositionelle streuen Gerüchte, dass die } \\
\text { Regierung heimlich Land an Usbekistan abgetreten habe und fordern die Einschaltung des russischen Präsi- } \\
\text { denten Wladimir Putin als Vermittler. }\end{array}$ \\
\hline 22.3 .2016 & $\begin{array}{l}\text { Der auf Initiative Kirgistans in Moskau außerplanmäßig zusammengetretene ständige Rat der CSTO-Staaten } \\
\text { drückt seine Beunruhigung über die Situation an der kirgisisch-usbekischen Grenze aus. }\end{array}$ \\
\hline 22.3 .2016 & $\begin{array}{l}\text { ach Angaben der Staatsanwaltschaft wurde die salafistische Gruppe Dschamaat at-Tauhid wal-Dschihad als } \\
\text { rroristische Gruppe in Kirgistan verboten. }\end{array}$ \\
\hline 22.3 .2016 & $\begin{array}{l}\text { Die Sicherheitskräfte melden die Verhaftung von vier Verdächtigen, darunter zwei ehemaligen Mitarbeitern des } \\
\text { Innenministeriums, wegen Menschenhandels. Sie sollen Frauen zwecks Prostitution nach Almaty gebracht haben. }\end{array}$ \\
\hline 23.3 .2016 & $\begin{array}{l}\text { Das staatliche Komitee für nationale Sicherheit bestätigt die Authentizität der zwei Tage zuvor im Internet auf- } \\
\text { getauchten Audiodateien, auf denen mehrere Männerstimmen die Möglichkeiten einer Destabilisierung der } \\
\text { politischen Lage Kirgistans mit anschließendem Umsturz erörtern. Es wird vermutet, dass die Stimmen den } \\
\text { Oppositionspolitikern Bektur Asanow, Kubanytschbek Kadyrow, Asimbek Beknasarow und Duulat Turdu- } \\
\text { nalijew gehören. Die Betroffenen betonen, dass in Kirgistan Redefreiheit herrsche. }\end{array}$ \\
\hline 23.3 .2016 & $\begin{array}{l}\text { Interpol meldet die Verhaftung von Adil Toiganbajew in Dubai. Dem ehemaligen Schwiegersohn von Ex-Prä- } \\
\text { sident Askar Akajew werden in Kirgistan illegale Privatisierung, Korruption und weitere Wirtschaftsvergehen } \\
\text { während Akaews Amtszeit vorgeworfen. }\end{array}$ \\
\hline 23.3 .2016 & $\begin{array}{l}\text { Das offizielle Kirgistan betont, dass der Berg Ungar-Too an der Grenze zu Usbekistan bislang nicht delimitiert } \\
\text { und demarkiert sei und dass der dort stationierte kirgisische Radiosender Kerben RRS-24 dort bestehen bleibt. }\end{array}$ \\
\hline
\end{tabular}




\begin{tabular}{|l|l|}
\hline 24.3.2016 & $\begin{array}{l}\text { Nach Angaben des Finanzministeriums hat Kirgistan in den letzten fünf Jahren insgesamt 3 Mrd. US-Dollar } \\
\text { von Geberländern und internationalen Finanzinstituten erhalten. Die meisten Kredite und Unterstützungs- } \\
\text { zahlungen flossen in den Transport- und Energiesektor. }\end{array}$ \\
\hline 24.3.2016 & $\begin{array}{l}\text { Präsident Atambajew empfängt den Leiter des Regionalen Zentrums für präventive Diplomatie der UN, Petko } \\
\text { Draganov, zu einem Gespräch über die regionale Sicherheit in Zentralasien. }\end{array}$ \\
\hline 24.3.2016 & $\begin{array}{l}\text { Russische Medien melden, dass sich ein 21jähriger der Nähe zum IS verdächtigter Kirgise während eines Ver- } \\
\text { hörs in Moskau aus dem Fenster zu Tode gestürzt habe. }\end{array}$ \\
\hline 24.3.2016 & $\begin{array}{l}\text { Innenminister Melis Turganbajew überreicht dem islamischen Theologen Kadyr Malikow, auf den im Novem- } \\
\text { ber 2015 ein Überfall verübt worden war, bei einem Treffen eine Gaspistole zur Selbstverteidigung. }\end{array}$ \\
\hline 24.3.2016 & $\begin{array}{l}\text { Präsident Atambajew droht, den SCO-Gipfel im Taschkent im Juni zu boykottieren, wenn die Grenzprobleme } \\
\text { bis dahin nicht gelöst sind. }\end{array}$ \\
\hline 24.3.2016 & $\begin{array}{l}\text { Die beiden Führer der Oppositionsbewegung El ünu (Volksstimme), Kadyrow und Asanow, werden wegen } \\
\text { des Verdachts der Planung einer Destabilisierung des Landes und anschließendem Umsturzversuch verhaftet. } \\
\text { Grundlage ist u. a. der drei Tage zuvor öffentlich gewordene Audiomitschnitt. }\end{array}$ \\
\hline 25.3.2016 & $\begin{array}{l}\text { Ein Gericht in Bischkek verurteilt einen Mitarbeiter der Sicherheitskräfte wegen Annahme von Schmiergel- } \\
\text { dern zu 12 Jahren Freiheitsentzug und Konfiszierung des Eigentums und seine Helferin zu einer Geldstrafe. }\end{array}$ \\
\hline 25.3.2016 & $\begin{array}{l}\text { Bei einem auf usbekischen Wunsch stattfinden Treffen des Chefs der kirgisischen Grenztruppen, Generalma- } \\
\text { jor Raimberdi Dujschenbijew, mit dem Kommandierenden der usbekischen Grenztruppen, Generalmajor Rus- } \\
\text { tam Emindschanow, wird die schwierige Situation an der gemeinsamen Grenze erörtert. }\end{array}$ \\
\hline $\begin{array}{l}\text { Sicherheitskräfte nehmen in Bischkek mehrere ihrer Kollegen fest, die einen Bürger Turkmenistans zur Erpres- } \\
\text { sung von Lösegeld entführt hatten. }\end{array}$ \\
\hline
\end{tabular}

\section{Tadschikistan}

\begin{tabular}{|c|c|}
\hline 20.2 .2016 & $\begin{array}{l}\text { Vor dem Gebäude der EU-Vertretung in Duschanbe demonstriert eine Gruppe junger Leute für die Auslieferung } \\
\text { des Führers der verbotenen Partei der Islamischen Wiedergeburt (PIWT), Muchiddin Kabiri, an Tadschikistan. }\end{array}$ \\
\hline 20.2 .2016 & $\begin{array}{l}\text { Die Polizei gibt die Verhaftung von Obid Maksudow, des Sohnes des Direktors des Kabelwerkes von Duschanbe, } \\
\text { wegen des Verdachts der Ermordung des Unternehmers Safar Asimow zwei Tage zuvor bekannt. Grund soll ein } \\
\text { Streit über mehr als } 100.000 \text { US-Dollar Schulden Asimows bei Maksudow gewesen sein. }\end{array}$ \\
\hline 22.2 .2016 & $\begin{array}{l}\text { Ein Gericht in Duschanbe verurteilt vier Männer wegen Drogenhandels zwischen Afghanistan, Tadschikistan } \\
\text { und Russland zu Freiheitsstrafen zwischen } 14 \text { und } 20 \text { Jahren. Bei ihrer Festnahme im November } 2015 \text { waren } \\
140 \mathrm{~kg} \text { Heroin, } 50 \mathrm{~kg} \text { Opium und mehr als } 1.000 \text { Ecstasy-Tabletten bei ihnen gefunden worden. }\end{array}$ \\
\hline 22.2 .2016 & $\begin{array}{l}\text { Ein Militärgericht in Kuljab verurteilt einen Angehörigen der Grenztruppen wegen Desertation und Extre- } \\
\text { mismus zu einer 17jährigen Haftstrafe. Der Angeklagte hatte zuvor gestanden, seine Einheit verlassen und die } \\
\text { afghanische Grenze überschritten zu haben. }\end{array}$ \\
\hline 22.2 .2016 & $\begin{array}{l}\text { RFE/RL meldet, dass } 14 \text { Bewohner des Bezirks Jowon (Gebiet Chatlon) verhaftet wurden, weil sie im russi- } \\
\text { schen sozialen Netzwerk Odnoklassniki ein islamistisches Video geliket hatten. Zehn wurden nach Befragung } \\
\text { entlassen, vier bleiben in U-Haft. }\end{array}$ \\
\hline 22.2 .2016 & $\begin{array}{l}\text { Die seit acht Monaten in Belarus inhaftierte Aktivistin der oppositionellen Gruppe 24, Schabnam Chudojdo- } \\
\text { dowa, wird nicht nach Tadschikistan ausgeliefert, sondern frei gelassen und erhält den Status einen politi- } \\
\text { schen Flüchtlings. }\end{array}$ \\
\hline 23.2 .2016 & $\begin{array}{l}\text { Im Gebiet Sogd werden acht junge Männer wegen Teilnahme an der verbotenen islamistischen Bewegung der } \\
\text { Salafiten zu dreieinhalb- bzw. vierjährigen Haftstrafen verurteilt. }\end{array}$ \\
\hline 23.2 .2016 & $\begin{array}{l}\text { Das Energieministerium meldet, dass ab sofort alle Einschränkungen der Stromversorgung im ganzen Land } \\
\text { aufgehoben sind. }\end{array}$ \\
\hline 24.2 .2016 & $\begin{array}{l}\text { Die EU drückt in einer Erklärung ihre Beunruhigung über die strafrechtliche Verfolgung der PIWT-Füh- } \\
\text { rungsmitglieder aus und fordert einen fairen Prozess. Die PIWT befinde sich nicht auf der Liste internationa- } \\
\text { ler terroristischer Organisationen. }\end{array}$ \\
\hline 24.2 .2016 & $\begin{array}{l}\text { AI kommt in seinem jährlichen Bericht zu dem Ergebnis, dass in Tadschikistan } 2015 \text { nicht nur wie bisher die } \\
\text { Meinungsfreiheit eingeschränkt und der Zugang ins Internet blockiert war, sondern zunehmender Druck auf } \\
\text { im und außerhalb des Landes befindliche Oppositionelle ausgeübt wurde, bis hin zum Mord. }\end{array}$ \\
\hline
\end{tabular}




\begin{tabular}{|c|c|}
\hline 24.2 .2016 & $\begin{array}{l}\text { Ein Gericht in Duschanbe verurteilt erstmals eine Frau wegen Teilnahme am syrischen Bürgerkrieg. Die 34jäh- } \\
\text { rige, der auch Anwerbung von Jugendlichen für den Krieg zur Last gelegt wird, erhält eine Freiheitsstrafe von } \\
13 \text { Jahren. }\end{array}$ \\
\hline 25.2 .2016 & $\begin{array}{l}\text { Mit Unterschrift des Präsidenten unter die entsprechende Verordnung erhält eine neue, an Stelle einer durch eine } \\
\text { Schlammlawine zerstörte Ortschaft im Bezirk Schugnan (GBAO) errichtete Siedlung den Namen Rachmonobod. }\end{array}$ \\
\hline 25.2 .2016 & $\begin{array}{l}\text { Vor dem OSZE-Büro in Chudschand versammeln sich einige Dutzend junger Leute und fordern die Ausliefe- } \\
\text { rung der »Vaterlandsverräter» der PIWT und Gruppe } 24 \text { an Tadschikistan. }\end{array}$ \\
\hline 25.2 .2016 & $\begin{array}{l}\text { Innenminister Ramasan Rahimsoda erörtert während seines Arbeitsbesuches in Beijing mit dem chinesischen } \\
\text { Minister für gesellschaftliche Sicherheit, Guo Shengkun, Möglichkeiten einer verstärkten Zusammenarbeit im } \\
\text { Bereich des Kampfes gegen Terrorismus, Separatismus und den Drogen- und Waffenhandel. }\end{array}$ \\
\hline 26.2.2016 & $\begin{array}{l}\text { Präsident Rachmon unterzeichnet den Beschluss über die Gründung einer medizinischen Hochschule in sei- } \\
\text { nem Heimatort Dangara (Gebiet Chatlon). Mit dieser zweiten Ausbildungsstätte für Ärzte soll dem Medizi- } \\
\text { nermangel im Land begegnet werden. }\end{array}$ \\
\hline 26.2.2016 & $\begin{array}{l}\text { Der tadschikische Dienst von RFE/RL meldet, dass Chumairo Mirowa, ehemalige Mitarbeiterin der Presseab- } \\
\text { teilung des Innenministeriums und Zweitfrau des im Sommer } 2015 \text { zum IS übergelaufenen ehemaligen Chefs } \\
\text { der tadschikischen OMON-Truppen, Gulmurod Chalimow, sich bereits seit längerem mit ihren vier Kindern } \\
\text { in Syrien aufhalte. }\end{array}$ \\
\hline 26.2 . & $\begin{array}{l}\text { Ein Gericht in Istanbul verurteilt Sulajmon Kajumow wegen der Ermordung des tadschikischen Exilopposi- } \\
\text { tionellen Umarali Kuwwatow im März } 2015 \text { zu einer lebenslänglichen Freiheitsstrafe. Kajumow hatte die töd- } \\
\text { lichen Schüsse nicht selber abgegeben, wird aber als Auftraggeber betrachtet. }\end{array}$ \\
\hline 29.2 .2016 & $\begin{array}{l}\text { Präsident Rachmon weist auf einer Regierungssitzung auf die wegen des schneearmen Winters und frühen } \\
\text { Frühlings drohende Gefahr von Wassermangel und Missernten hin und fordert die Bevölkerung zum sparsa- } \\
\text { men Umgang mit Wasser und zur Bevorratung von Lebensmitteln auf. }\end{array}$ \\
\hline 29.2 .2016 & $\begin{array}{l}\text { Das Rektorat der Islamischen Universität in Duschanbe droht Studenten, die Websites islamistischen Inhalts - } \\
\text { ausdrücklich auch der PIWT - aufrufen, die Exmatrikulation an. }\end{array}$ \\
\hline 1.3 .2016 & $\begin{array}{l}\text { Präsident Rachmon empfängt den Kommandierenden der pakistanischen Streitkräfte, Rachil Sharif. Zuvor } \\
\text { hatte Sharif bereits Gespräche über Fragen der bilateralen Zusammenarbeit und der regionalen Sicherheit mit } \\
\text { Verteidigungsminister Scherali Mirso geführt. }\end{array}$ \\
\hline 1.3 .2016 & $\begin{array}{l}\text { Der chinesische Sonderbeauftragte für den Kampf gegen den Terrorismus, Cheng Guoping, trifft in Duschanbe } \\
\text { mit Präsident Rachmon und Innenminister Rahimsoda zu Gesprächen über die Zusammenarbeit im Sicher- } \\
\text { heitsbereich und die Situation in Afghanistan zusammen. }\end{array}$ \\
\hline 1.3 .2016 & $\begin{array}{l}\text { Das private Nachrichtendienst Awesta berichtet, dass an einigen Fakultäten der Nation } \\
\text { der Kurs »Emomali Rachmon - Der Architekt eines neuen Staates des tadschikisches }\end{array}$ \\
\hline 2.3 .2016 & $\begin{array}{l}\text { n Gericht im Bezirk Farchor (Gebiet Chatlon) verurteilt drei Männer wegen Extremismus, Anhängerschaft } \\
\text { d Propaganda für den IS zu Freiheitsstrafen zwischen fünfeinhalb und } 14 \text { Jahren. }\end{array}$ \\
\hline 3.3 .2016 & $\begin{array}{l}\text { Der Senat beschließt in Reaktion auf einen Vorschlag der Regierung die Schaffung des Amtes eines Ombuds- } \\
\text { mannes für Kinderrechte. }\end{array}$ \\
\hline 3.3 .2016 & $\begin{array}{l}\text { Der Senat beschließt einstimmig Gesetzesänderungen, die erniedrigende und ehrverletzende Vornamen und } \\
\text { Eheschließungen zwischen nahen Verwandten verbieten sowie die vom Präsidenten vorgeschlagenen Verände- } \\
\text { rungen von Bezirks- und Ortsnamen. Z. B. wird Kairakkum nun Guliston heißen, der nach dem Ort benannte } \\
\text { Stausee Bachri Totschik (Tadschikisches Meer). }\end{array}$ \\
\hline 4.3 .2016 & $\begin{array}{l}\text { In Duschanbe nimmt im Beisein von Präsident Rachmon das größte medizinische Zentrum Tadschikistans } \\
\text { die Arbeit auf. Die für } 706 \text { Mio. Somoni (mehr als } 11 \text { Mio. US-Dollar) errichtete Anlage umfasst ein Kran- } \\
\text { kenhaus mit } 650 \text { Betten und eine Poliklinik. }\end{array}$ \\
\hline 4.3 .2016 & $\begin{array}{l}\text { Asia-Plus berichtet, dass Angehörige der inhaftierten PIWT-Führer erstmals seit mehreren Wochen ihre Ver- } \\
\text { wandten treffen konnten und ihnen das Zuhören bei den Gerichtsverhandlungen gestattet wurde. }\end{array}$ \\
\hline 5.3 .2016 & $\begin{array}{l}\text { Bei dem Versuch im Bereich des Grenzpostens Pjandsch (Gebiet Chatlon) das Eindringen von neun Personen } \\
\text { aus Afghanistan zu verhindern, kommt ein Wehrdienstleistender ums Leben. Einer der Insurgenten wird eben- } \\
\text { falls erschossen, ein weiterer schwer verletzt. }\end{array}$ \\
\hline 6.3 .2016 & $\begin{array}{l}\text { Anlässlich des bevorstehenden 25. Jubiläums des unabhängigen Tadschikistan schreibt Präsident Rachmon } \\
\text { einen Wettbewerb zwischen den Staatsorganen um die schönste Stadt aus. }\end{array}$ \\
\hline
\end{tabular}




\begin{tabular}{|c|c|}
\hline 6.3 .2016 & $\begin{array}{l}\text { Außenminister Sirodschiddin Aslow nimmt an der Sitzung der Außenminister der Staaten der Organisation } \\
\text { für Islamische Zusammenarbeit (OIC) im indonesischen Jakarta teil. Am Rande der Veranstaltung trifft Aslow } \\
\text { mit seinen Amtskollegen aus Indonesien, Afghanistan und Iran, Retno Marsudi, Salahuddin Rabbani und } \\
\text { Mohammed Dschawad Sarif, zusammen. }\end{array}$ \\
\hline 7.3.2016 & $\begin{array}{l}\text { Ein Gericht in Isfara (Gebiet Sogd) verurteilt den 72jährigen örtlichen Vorsitzenden der verbotenen PIWT, Abdu- } \\
\text { sattor Bobojew, wegen Zugehörigkeit zu einer extremistischen Organisation und extremistischer Tätigkeit zu } \\
\text { einer 11jährigen Gefängnisstrafe. Zwei weitere Parteimitglieder erhalten sechs- bzw. siebenjährige Freiheitsstrafen. }\end{array}$ \\
\hline 9.3 .2016 & $\begin{array}{l}\text { Die Abgeordneten des Unterhauses des Parlamentes verabschieden eine Änderung des Strafgesetzbuches, mit } \\
\text { der das Strafmaß für Devisenvergehen auf bis zu neun Jahre Freiheitsentzug oder die Zahlung von } 65.680 \\
\text { Somoni (ca. 8.300 US-Dollar) angehoben wird. }\end{array}$ \\
\hline 9.3 .2016 & $\begin{array}{l}\text { Der UN-Sonderberichterstatter für Meinungsfreiheit, David Kaye, äußert sich auf einer Pressekonferenz am } \\
\text { Ende seines mehrtägigen Tadschikistanbesuches, bei dem er mit dem stellvertretenden Außenminister Nis- } \\
\text { omiddin Sohidi, Mitarbeitern des Justiz- und Innenministeriums sowie Vertretern von NGOs und Medien } \\
\text { zusammengetroffen war, beunruhigt über fehlende Pressefreiheit, die Verfolgung der PIWT und das bevorste- } \\
\text { hende Verfassungsreferendum. }\end{array}$ \\
\hline 11.3 .2016 & $\begin{array}{l}\text { Tadschikische Medien melden, dass Präsident Rachmon neben den Staatschefs von China, Indien, Mexiko und } \\
11 \text { weiteren Staaten für zwei Jahre zum Mitglied des United Nations High-Level Panel on Water gewählt wurde. }\end{array}$ \\
\hline 14.3 .2016 & $\begin{array}{l}\text { In Moskau werden bei einer Massenschlägerei zwischen usbekischen und tadschikischen Arbeitsmigranten } 28 \\
\text { Personen festgenommen. Ursache soll ein Alltagskonflikt gewesen sein. }\end{array}$ \\
\hline 14.3 .2016 & $\begin{array}{l}\text { RFE/RL meldet, dass mit Daler Tabarow ein weiterer Sohn des Anwalts Ischok Tabarow, des Verteidigers des } \\
2013 \text { zu einer 29jährigen Freiheitsstrafe verurteilten Oppositionellen Said Saidow, strafrechtlich verfolgt wird. } \\
\text { Sein erster Sohn wurde bereits wegen antistaatlicher Propaganda zu 13,5 Jahren Freiheitsentzug verurteilt; Sai- } \\
\text { dows zweiter Anwalt sitzt ebenfalls für neun Jahre in Haft. }\end{array}$ \\
\hline 15.3 & $\begin{array}{l}\text { Im Bereich der tadschikisch-afghanischen Grenze findet ein mehrtägiges gemeinsames Manöver der tadschiki- } \\
\text { schen und russischen Streitkräfte statt, an dem } 2.000 \text { russische und } 50.000 \text { tadschikische Soldaten und Reser- } \\
\text { visten mit schwerer Militärtechnik und Bombern vom Typ Tu-22M3 teilnehmen. }\end{array}$ \\
\hline 15.3 .2016 & $\begin{array}{l}\text { Im Rahmen seines mehrtägigen Besuches in Islamabad trifft Parlamentssprecher Schukurdschon Suchurow mit } \\
\text { dem Sprecher der pakistanischen Volksvertretung, Sardar Ayaz Sadiq, zusammen. Gespräche mit Senatsspre- } \\
\text { cher Mian Raza Rabbani und dem Berater des Premierministers für Außenpolitik, Toriq Fotimi, werden folgen. }\end{array}$ \\
\hline 16.3 .2016 & $\begin{array}{l}\text { Während des zweitägigen Besuches in den VAE wird Präsident Rachmon von Scheich Muhammad bin Zayid } \\
\text { Al Nahyan, dem Bruder des Emirs und Premierministers und stellvertretenden Kommandierenden der Streit- } \\
\text { kräfte der VAE, und dem Generaldirektor des Entwicklungsfonds von Abu Dhabi, Mohammed Saif Al Suwaidi, } \\
\text { empfangen und eröffnet das neue Gebäude der Botschaft Tadschikistans in Abu Dhabi. }\end{array}$ \\
\hline 18.3 .2016 & $\begin{array}{l}\text { Die in Tadschikistan seit September } 2015 \text { blockierten sozialen Netzwerke, Odnoklassniki, Facebook, Vkon- } \\
\text { takte und Youtube sind bei allen Providern wieder zugänglich. }\end{array}$ \\
\hline 19.3 .2016 & $\begin{array}{l}\text { Nach Angaben der russischen Zentralbank sanken die Rücküberweisungen tadschikischer Arbeitsmigranten } \\
\text { aus Russland } 2015 \text { auf 1,3 Mrd. US-Dollar (2014 waren es noch 3,9 Mrd. gewesen). }\end{array}$ \\
\hline 24.3 .2016 & $\begin{array}{l}\text { In Anwesenheit von Präsident Rachmon wird in Kanibadam (Gebiet Sogd) ein für 3,5 Mio. Somoni ( } 445.000 \\
\text { US-Dollar) errichtetes erdölverarbeitendes Werk eröffnet, das jährlich 70.000 t Rohöl verarbeiten soll. }\end{array}$ \\
\hline 25.3 .2016 & $\begin{array}{l}\text { Der tadschikische Dienst von RFE/RL meldet, dass bei einem bewaffneten Übergriff afghanischer Schmuggler } \\
\text { auf ein Straßenbauprojekt im Bezirk Schuroobod (Gebiet Chatlon) mehrere Personen getötet wurden. }\end{array}$ \\
\hline
\end{tabular}

\section{Turkmenistan}

\begin{tabular}{|l|l|}
\hline 20.2.2016 & $\begin{array}{l}\text { Im Auftrag der Stadtverwaltung werden erneut Satellitenantennen in mehreren Stadtteilen Aschchabads } \\
\text { demontiert. }\end{array}$ \\
\hline 20.2.2016 & $\begin{array}{l}\text { Die staatliche Nachrichtenagentur TDCh meldet, dass die Glaskabelverbindungen der Turkmentelekom mit } \\
\text { den Nachbarstaaten in den kommenden Jahren ausgebaut werden sollen, um die Geschwindigkeit der Daten- } \\
\text { übertragung massiv zu steigern. }\end{array}$ \\
\hline
\end{tabular}




\begin{tabular}{|c|c|}
\hline 24.2 .2016 & $\begin{array}{l}\text { Das oppositionelle Nachrichtenportal Gündogar meldet, dass die Arbeit auf zahlreichen Baustellen in Asch- } \\
\text { chabad, darunter auch solche für die Asien-Spiele für Hallensportarten 2017, ruht, da viele aus anderen Teilen } \\
\text { des Landes zugereiste Bauarbeiter von den Behörden aus angemieteten Wohnungen vertrieben wurden. Meh- } \\
\text { rere Firmen haben deshalb ihre Arbeiterquartiere ins Umland verlegt. Mehrere ausländische Bauunterneh- } \\
\text { men, darunter die türkischen Konzerne Norsel und Gap Insaat, haben ihre Tätigkeit in Turkmenistan einge- } \\
\text { stellt. Andere Firmen wie die französische Bouygues und die österreichische Schlumberger haben bis zu } 70 \% \\
\text { ihrer Mitarbeiter entlassen. }\end{array}$ \\
\hline 24.2 .2016 & $\begin{array}{l}\text { Das Außenministerium gibt bekannt, dass Turkmenistan seit 16.2. offiziell Mitgliedsstaat der IAEA (Interna- } \\
\text { tionale Atomenergiebehörde) ist. }\end{array}$ \\
\hline 25.2 .2016 & $\begin{array}{l}\text { In der georgischen Hauptstadt Tbilisi finden georgisch-turkmenische Regierungskonsultationen unter Lei- } \\
\text { tung der stellvertretenden Außenminister beider Staaten, Dawid Dschalaganija und Wepa Hadschijew, statt. }\end{array}$ \\
\hline 25.2 .2016 & $\begin{array}{l}\text { Der afghanische Vize-Premier und Chef der Nationalen Islamischen Bewegung, General Abdul Raschid Dos- } \\
\text { tum, kündigt eine breit angelegte Offensive gegen die Taliban in der an Turkmenistan grenzenden Provinz } \\
\text { Dschauskhan und, laut der Nachrichtenagentur Pajhwok Afghan News, einen Besuch im Nachbarland zur } \\
\text { Koordinierung des Einsatzes an. }\end{array}$ \\
\hline 28.2.2016 & $\begin{array}{l}\text { Eine Delegation von Abgeordneten unter Leitung der Parlamentssprecherin Akdscha Nurberdyjewa trifft in } \\
\text { Wien zur alljährlichen Parlamentarischen Versammlung der OSZE ein. }\end{array}$ \\
\hline 1.3 .2016 & $\begin{array}{l}\text { Im Erholungsressort Awasa am Kaspischen Meer treffen die Leiter der Eisenbahn- und Hafenbehörden Turkme- } \\
\text { nistans, Aserbaidschans, Kasachstans, Irans und Georgiens zu Gesprächen über den Ausbau regionaler Trans- } \\
\text { portkorridore in Süd-Nord- und Ost-West-Richtung zusammen. }\end{array}$ \\
\hline 2.3 .2016 & $\begin{array}{l}\text { Bei einer Sitzung des Nationalen Sicherheitsrates rügt Präsident Gurbanguly Berdymuchammedow den stell- } \\
\text { vertretenden Innenminister, Jasdurdy Sojegow, scharf für Nachlässigkeiten bei der Kontrolle des Zuzugs von } \\
\text { Personen aus den Gebieten des Landes nach Aschchabad. Zum neuen Polizeichef Aschchabads wird Abygafur } \\
\text { Beknasarow ernannt, sein Vorgänger, Gurbangeldy Bairamow, war am 14.2. entlassen worden. Der Minister } \\
\text { für Nationale Sicherheit, Gujtschgeldy Chodschaberdyjew, erst seit Oktober } 2015 \text { im Amt, wird aus gesund- } \\
\text { heitlichen Gründen durch den bisherigen Chef der Zollbehörde, Dowrangeldy Bairamow ersetzt; der Chef des } \\
\text { Grenzsicherheitsdienstes, Murad Islamow, durch Begentsch Gundogdyjew. }\end{array}$ \\
\hline 3.3 .2016 & $\begin{array}{l}\text { Der Berater des afghanischen Präsidenten für nationale Sicherheit, Chanif Atmar, trifft in Aschchabad mit } \\
\text { dem turkmenischen Verteidigungsminister Jaylym Berdijew zu Gesprächen über die Sicherheit der TAPI-Pipe- } \\
\text { line zusammen. }\end{array}$ \\
\hline 4.3 .2016 & $\begin{array}{l}\text { Präsident Berdymuchammedow entlässt bei einer erweiterten Kabinettssitzung den Chef des Meteorologischen } \\
\text { Dienstes, Batyr Chalyjew, wegen falscher Wettervorhersagen. Der Chef des Statistikamtes, Akmyrat Mamme- } \\
\text { dow, wird wegen Schönung von Statistiken seines Amtes enthoben. }\end{array}$ \\
\hline 5.3 .2016 & $\begin{array}{l}\text { Präsident Berdymuchammedow kritisiert in einer im Fernsehen übertragenen Ansprache an das Kabinett die } \\
\text { ausufernde Korruption. Der im November wegen Schmiergeldannahme entlassene ehemalige Vize-Premier } \\
\text { Baimurat Chodschamuchammedow hat nach Angaben von Berdymuchammedow den dem Staatshaushalt } \\
\text { entstandenen Schaden von 1,5 Mio. US-Dollar zurückgezahlt. }\end{array}$ \\
\hline 7.3.2016 & $\begin{array}{l}\text { In Aschchabad finden bilaterale Gespräche zwischen Präsident Berdymuchammedow und dem Emir von Katar, } \\
\text { Tamim bin Hamad al-Thani, über Stand und Perspektiven der Zusammenarbeit statt. }\end{array}$ \\
\hline 11.3 .2016 & $\begin{array}{l}\text { Das Nachrichtenportal Alternativnye nowosti Turkmenistana (ANT) meldet, dass die Klage des türkischen } \\
\text { Baukonzerns Ickale Insaat gegen die turkmenische Regierung zur Zahlung von } 567 \text { Mio. US-Dollar Schadens- } \\
\text { ersatz vom Schiedsgericht der Weltbank abgewiesen wurde. }\end{array}$ \\
\hline 13.3 .2016 & $\begin{array}{l}\text { Der Sonderbeauftragte der EU für Zentralasien, Peter Burian, trifft zu Gesprächen mit Parlamentariern und } \\
\text { den Führungen mehrerer Ministerien in Aschchabad ein. }\end{array}$ \\
\hline 15.3.2016 & $\begin{array}{l}\text { Der Außenminister von Burkina Faso, Alpha Mamadou Barry, trifft in Aschchabad zu Gesprächen ein und } \\
\text { unterzeichnet ein Abkommen zur Aufnahme turkmenisch-burkinesischer diplomatischer Beziehungen. }\end{array}$ \\
\hline 16.3 .2016 & $\begin{array}{l}\text { Präsident Berdymuchammedow wird während seines zweitägigen Staatsbesuches in Islamabad von seinem } \\
\text { pakistanischen Amtskollegen Mamnoon Hussain und Premierminister Nawaz Sharif zu Gesprächen über das } \\
\text { TAPI-Projekt und die Perspektiven der bi- und multilateralen Zusammenarbeit empfangen. }\end{array}$ \\
\hline 16.3 .2016 & $\begin{array}{l}\text { Die russische Nachrichtenagentur Interfax meldet, dass der Liefervertrag für turkmenisches Gas an Russland } \\
\text { von der russischen Gazprom Anfang des Jahres wegen der geringen Kooperationsbereitschaft der turkmeni- } \\
\text { schen Seite gekündigt wurde. }\end{array}$ \\
\hline
\end{tabular}




\begin{tabular}{|l|l|}
\hline 16.3.2016 & $\begin{array}{l}\text { Während der Vorstellung eines Bericht des Instituts Chatham House zur innen- und außenpolitischen Lage in } \\
\text { Turkmenistan im Europäischen Parlament in Brüssel bringen mehrere Abgeordnete und Vertreter der Exilop- } \\
\text { position ihre Sorge über schwere Menschenrechtsverletzungen in dem Land zum Ausdruck. }\end{array}$ \\
\hline 19.3.2016 & $\begin{array}{l}\text { Es findet ein landesweiter samstäglicher Arbeitseinsatz (Subbotnik) zur Pflanzung von drei Millionen Nadel- } \\
\text { bäumen statt. }\end{array}$ \\
\hline 19.3.2016 & $\begin{array}{l}\text { Präsident Berdymuchammedow unterzeichnet ein Gesetz, das ein Staatsmonopol auf die Einfuhr und den } \\
\text { Verkauf von Tabakwaren festschreibt. Die Einfuhr von zwei Päckchen Zigaretten pro Person für den persön- } \\
\text { lichen Bedarf bleibt legal. }\end{array}$ \\
\hline 20.3.2016 & $\begin{array}{l}\text { In Aschchabad findet eine »Fahrraddemo« statt, an der mehrere Vizeminister und zahlreiche Studenten und } \\
\text { Staatsbedienstete teilnehmen. Präsident Berdymuchammedow, der derartige Veranstaltungen in der Regel } \\
\text { anführt, ist derweil mit der Vorstellung eines neuen Buches über die Pferderasse der Achal-Tekiner beschäftigt. }\end{array}$ \\
\hline 21.3.2016 & $\begin{array}{l}\text { Präsident Berdymuchammedow bespricht in einem Telefonat mit seinem afghanischen Amtskollegen Ashraf } \\
\text { Ghani Fragen des Baus der TAPI-Gaspipeline. }\end{array}$ \\
\hline 24.3.2016 & $\begin{array}{l}\text { Die Chefin der Autonomen territorialen Struktur Gagausien der Republik Moldau, Irina Wlach, trifft in Asch- } \\
\text { chabad zu Gesprächen mit Präsident Berdymuchammedow zusammen. }\end{array}$ \\
\hline 24.3.2016 & $\begin{array}{l}\text { In Aschchabad finden turkmenisch-saudische Regierungskonsultationen zu Fragen der bilateralen Wirtschafts- } \\
\text { und Handelskooperation statt. }\end{array}$ \\
\hline
\end{tabular}

\section{Usbekistan}

\begin{tabular}{|c|c|}
\hline 20.2 .2016 & $\begin{array}{l}\text { Die Mahalla des Wohnortes der Familie des unter obskuren Umständen am Vortag in der Stadt Pachtakor } \\
\text { (Gebiet Dschissak) als Islamist verurteilten Aramais Awakjan beschließt die Ausweisung seiner Ehefrau und } \\
\text { ihrer beiden Kinder wegen der Straftaten des Mannes und der Verbreitung von Gerüchten. }\end{array}$ \\
\hline 21.2 .2016 & $\begin{array}{l}\text { Der ehemalige Gouverneur des Gebietes Taschkent, Achmadschon Usmanow, wird verhaftet. Bereits unmit- } \\
\text { telbar nach seiner Absetzung am 4.2. hatte eine Pressekampagne gegen ihn begonnen, bei der ihm Misserfolge } \\
\text { bei der Arbeit und Korruption vorgeworfen wurden. }\end{array}$ \\
\hline 22.2 .2016 & $\begin{array}{l}\text { Auf Verordnung von Präsident Islam Karimow wird das bisherige Ministerium für Arbeit und sozialen Schutz } \\
\text { der Bevölkerung umgebildet in ein Arbeitsministerium. Die Abteilungen für sozialen Schutz gehen an das } \\
\text { Gesundheitsministerium, die für Festsetzung und Auszahlungen materieller Hilfe an das Finanzministerium. }\end{array}$ \\
\hline 23.2 .2016 & $\begin{array}{l}\text { Der usbekische Dienst von RFE/RL meldet, dass eine der größten Chemiefabriken des Landes, das usbekisch- } \\
\text { spanische Joint Venture Ammofos-Maxam, seinen Arbeitern seit November } 2015 \text { keine Löhne mehr gezahlt } \\
\text { habe. Die Produktion läuft aber im vollen Umfang weiter. }\end{array}$ \\
\hline 23.2 .2016 & Ungarn eröffnet eine Botschaft in Taschkent. \\
\hline 24.2 .2016 & $\begin{array}{l}\text { Mit Unterschrift Präsident Karimows tritt eine Verordnung über die Änderung des Systems der Verwaltun- } \\
\text { gen von Gebieten, Städten und Bezirken in Kraft, u. a. gibt es nun auf Gebietsebene sechs statt wie bisher fünf } \\
\text { stellvertretende Gouverneure. }\end{array}$ \\
\hline 25.2 .2016 & $\begin{array}{l}\text { Usbekische Medien melden, dass der } 2013 \text { begonnene Bau der elektrifizierten Eisenbahnstrecke Angren-Pap, } \\
\text { die das Ferganatal unter Umgehung tadschikischen Staatsgebietes mit dem restlichen Usbekistan verbindet, } \\
\text { abgeschlossen ist. }\end{array}$ \\
\hline 22.2 .2016 & $\begin{array}{l}\text { In Taschkent findet die erste Sitzung des Lenkungsausschusses des Büros der Vereinten Nationen für Drogen- } \\
\text { und Verbrechensbekämpfung (UNODC) für Zentralasien statt, bei der Vertreter von Ministerien und zustän- } \\
\text { digen Behörden aus allen Staaten Zentralasiens den Stand der Implementierung des UN-Antidrogenprogram- } \\
\text { mes in der Region erörtern. }\end{array}$ \\
\hline 25.2 .2016 & $\begin{array}{l}\text { Am Rande der 4. Sitzung der bulgarisch-usbekischen Zwischenregierungskommission für ökonomische und } \\
\text { wissenschaftlich-technische Zusammenarbeit in Taschkent treffen die bulgarischen Ministerin für regionale } \\
\text { Entwicklung, Lilyana Pavlova, und der usbekische Minister für Außenwirtschaftsbeziehungen, Eljor Ganijew, } \\
\text { zu Gesprächen zusammen. Der bulgarische Wirtschaftsminister Bozhidar Lukarski erörtert mit seiner usbeki- } \\
\text { schen Amtskollegin Galina Saidowa Fragen der bilateralen Zusammenarbeit. }\end{array}$ \\
\hline 25.2 .2016 & $\begin{array}{l}\text { Der usbekische Dienst von RFE/RL meldet, dass die Generalstaatsanwaltschaft auf Betreiben des Nationalen } \\
\text { Sicherheitsdienstes gegen die usbekischen Verfasser eines vor drei Jahren unter UN-Ägide in Taschkent veröf- } \\
\text { fentlichten Leitfadens für die Leitung von Diskussionen ermittelt. Ihnen wird ein Angriff auf den verfassungs- } \\
\text { mäßigen Aufbau des Landes, Terrorismus und Verbreitung von die gesellschaftliche Ordnung bedrohenden } \\
\text { Materialien vorgeworfen. }\end{array}$ \\
\hline
\end{tabular}




\begin{tabular}{|c|c|}
\hline 26.2 .2016 & $\begin{array}{l}\text { Am frühen Morgen muss eine Maschine der russischen Fluggesellschaft AZUR Air mit } 327 \text { Passagieren an } \\
\text { Bord auf dem Weg von Moskau ins thailändische Phuket wegen technischer Probleme außerplanmäßig auf } \\
\text { dem Flughafen von Taschkent landen. }\end{array}$ \\
\hline 29.2 .2016 & $\begin{array}{l}\text { In Moskau wird die 38jährige Usbekin Gjultschechra Bobokulowa unter dem Verdacht festgenommen, eine ihr } \\
\text { als Kindermädchen anvertraute Vierjährige ermordet zu haben. Die verwirrt wirkende Frau war in einer Metro- } \\
\text { station mit dem abgetrennten Kopf des Kindes und »Allahu Akbar« rufend aufgegriffen worden. Nach ihrer } \\
\text { Festnahme wird bekannt, dass sie an Schizophrenie leidet; sie soll aber auch erklärt haben, der Mord sei Rache } \\
\text { an Wladimir Putin für den russischen Militäreinsatz in Syrien. Russische Staatsmedien berichten zunächst } \\
\text { nicht von dem Vorfall, mutmaßlich um Ausschreitungen gegen zentralasiatische Migranten vorzubeugen. }\end{array}$ \\
\hline 1.3 .2016 & $\begin{array}{l}\text { Ein Berufungsgericht im schwedischen Sundsvall erhöht die Strafe vom 15.12.2015 gegen den wegen des Mord- } \\
\text { anschlages auf den im schwedischen Exil lebenden Imam Obidchon Nasarow } 2012 \text { verurteilten usbekischen } \\
\text { Staatsbürger Jurij Dschukowskij von } 18 \text { Jahren auf lebenslänglich. Wenig später wird ein Haftbefehl für den } \\
\text { russischen Staatsbürger Tigran Kaplanow erlassen, der Dschukowskij angeworben haben soll. }\end{array}$ \\
\hline 2.3 .2016 & $\begin{array}{l}\text { Das International Labor Rights Forum verleiht seinen Labor Rights Defenders Award-2016 an die usbeki- } \\
\text { schen Menschenrechtler Jelena Urlajewa, Dmitrij Tichonow und Uktam Pardajew für ihr Engagement gegen } \\
\text { das staatliche System von Zwangsarbeit in der Baumwollernte. }\end{array}$ \\
\hline 2.3 .2016 & $\begin{array}{l}\text { Der usbekische Dienst von RFE/RL meldet, dass am 16.2. maskierte Sicherheitskräfte im Bezirk Altyaryk } \\
\text { (Gebiet Fergana) bei Haussuchungen } 11 \text { junge Männer unter dem Verdacht der Mitgliedschaft in der verbote- } \\
\text { nen islamistischen Hizb ut-Tahrir verhaftet haben. }\end{array}$ \\
\hline 2.3 .2016 & $\begin{array}{l}\text { Das Ministerkabinett verabschiedet Regeln ethischen Verhaltens für Staatsbedienstete und Organe der örtli- } \\
\text { chen Verwaltung, deren Übertretung mit Disziplinarstrafen geahndet werden kann. Zu den geforderten Wer- } \\
\text { ten gehören rechtmäßiges Handeln, Vorrang der Rechte und gesetzmäßigen Interessen der Bürger, Patriotis- } \\
\text { mus, Gerechtigkeit und Ehrlichkeit. }\end{array}$ \\
\hline 4.3 .2016 & $\begin{array}{l}\text { Nach Angaben des usbekischen Wetterdienstes war der vergangene Winter in Usbekistan um 4,2 Grad Cel- } \\
\text { sius wärmer als das langjährige Mittel. }\end{array}$ \\
\hline 4.3 .2016 & $\begin{array}{l}\text { In Usbekistan werden Verwandte und Nachbarn der Kindermörderin von Moskau, Gultschechra Bobokulowa, } \\
\text { wegen Terrorismusverdacht verhört oder festgenommen. }\end{array}$ \\
\hline 5.3 .2016 & $\begin{array}{l}\text { UzA meldet, dass am 26.2. die Assoziation der Rentner als Interessensvertretung der älteren Generation regis- } \\
\text { triert wurde und damit offiziell die Tätigkeit aufnehmen kann. Die Gründungsversammlung hatte bereits im } \\
\text { November } 2015 \text { stattgefunden. }\end{array}$ \\
\hline 9.3 .2016 & $\begin{array}{l}\text { Vertreter der Cotton Campaign übergeben in New York eine von } 140.000 \text { Menschen unterzeichnete Petition } \\
\text { an Weltbank-Präsident Jim Yong Kim, in der das Institut aufgefordert wird, die Förderung von landwirtschaft- } \\
\text { lichen Projekten in Usbekistan solange einzustellen, bis die Zwangsarbeit bei der Baumwollernte beendet ist. }\end{array}$ \\
\hline 14.3 .2016 & $\begin{array}{l}\text { as Staatskomitee für Privatisierung gibt bekannt, dass } 49 \% \text { der Aktien des größten Chemiewerkes des Lan- } \\
\text { es Navoiazot und } 35,9 \% \text { der größten Zementfabrik Kyzylkumzement zum Verkauf stehen. }\end{array}$ \\
\hline 15.3 .2016 & $\begin{array}{l}\text { RIA Nowosti meldet, dass die russische Gazprom und Uzbekneftegaz einen Gasliefervertrag über } 4 \text { Mrd. } \mathrm{m}^{3} \\
\text { für } 2016 \text { unterzeichnet haben. }\end{array}$ \\
\hline 15.3.2016 & $\begin{array}{l}\text { ußenminister Abdulasis Kamilow trifft während seines Chinabesuches in Beijing mit dem Generalsekretär } \\
\text { er SCO, Raschid Alimow, zusammen. }\end{array}$ \\
\hline 15.3.2016 & $\begin{array}{l}\text { RFE/RL meldet unter Berufung auf usbekische Sicherheitskreise, dass sich ein führender Mitarbeiter der Abtei- } \\
\text { lung für Technik und Finanzen des Nationalen Sicherheitsdienstes am 6.3. erschossen hat, nachdem die Abtei- } \\
\text { lung wegen Unterschlagung unter Verdacht geraten war. }\end{array}$ \\
\hline 16.3 .2016 & $\begin{array}{l}\text { Die kommunalen Versorgungsunternehmen kündigen für Taschkent zum 1.4. Preiserhöhungen für Heizung } \\
\text { und warmes Wasser um 9\% und kaltes Wasser um 5,7\% an. Gas und Strom werden zum gleichen Zeitpunkt } \\
\text { in ganz Usbekistan um 8,2\% bzw. 8,7\% teurer. }\end{array}$ \\
\hline 18.3 .2016 & $\begin{array}{l}\text { In Taschkent wird der Grundstein für den Neubau der Dschurabek-Moschee gelegt. Das Gotteshaus war Ende } \\
\text { April } 2015 \text { durch einen Brand zerstört worden. }\end{array}$ \\
\hline 19.3.2016 & $\begin{array}{l}\text { Nach Angaben der russischen Zentralbank sanken die Rücküberweisungen usbekischer Arbeitsmigranten aus } \\
\text { Russland } 2015 \text { um mehr als } 60 \% \text { auf 2,37 Mrd. US-Dollar. } 2014 \text { waren es noch 5,65 Mrd. US-Dollar gewesen. }\end{array}$ \\
\hline 19.3.2016 & $\begin{array}{l}\text { Nach dem Erscheinen eines wissenschaftlichen Aufsatzes berichten viele usbekische Medien über den Fund } \\
\text { einer neuen, dem Tyrannosaurus rex verwandte Saurierart in der Wüste Kysylkum. Der von russischen, ameri- } \\
\text { kanischen und englischen Paläontologen entdeckte Timurlengia euotica soll vor } 90 \text { Mio. Jahren gelebt haben. }\end{array}$ \\
\hline
\end{tabular}




\begin{tabular}{|c|c|}
\hline 19.3.2016 & $\begin{array}{l}\text { Im russischen Sankt Petersburg wird ein 32jähriger usbekischer Staatsbürger verhaftet, der wegen des Verdachts } \\
\text { einer Verschwörung gegen Präsident Karimow mit internationalem Haftbefehl gesucht wurde. }\end{array}$ \\
\hline 19.3.2016 & $\begin{array}{l}\text { Beim Absturz während der Landung eines Flugzeugs der Gesellschaft FlyDubai von Dubai nach Rostow am } \\
\text { Don kommt auch eine usbekische Staatsbürgerin ums Leben. }\end{array}$ \\
\hline 20.3 . & $\begin{array}{l}\text { Beim Zusammenstoß zweier Güterzüge bei Chawas (Gebiet Syrdarja) wurde ein Lokführer verletzt und es } \\
\text { entstand erheblicher Sachschaden, meldet der usbekische Dienst von RFE/RL. }\end{array}$ \\
\hline 22.3.2016 & $\begin{array}{l}\text { Ein Berufungsgericht in Dschissak bestätigt das umstrittene Urteil gegen Aramais Awakjan, Furkat Dschura- } \\
\text { jew und weitere wegen Extremismus und Terrorismus Verurteilte vom 19.2.2016. }\end{array}$ \\
\hline 23.3.2016 & $\begin{array}{l}\text { Nach Angaben des staatlichen Komitees für Statistik betrug die Zahl der usbekischen Staatsbürger am 1.1.2016 } \\
\text { 31.576.400, d. i. eine Steigerung gegenüber dem Vorjahr um 553.900 Personen, bzw. 1,8 \%. }\end{array}$ \\
\hline 23.3 .2016 & $\begin{array}{l}\text { Das Uzbek-German Forum for Human Rights veröffentlicht seinen neuesten Report über Zwangsarbeit bei } \\
\text { der Baumwollernte in Usbekistan } 2015 .\end{array}$ \\
\hline 23.3.2016 & $\begin{array}{l}\text { Nach Angaben von gazeta.uz wurden im Rahmen einer zwischen 20.2. und 20.3.2016 durchgeführten Anti- } \\
\text { Terror-Aktion } 260 \text { Ausländer aus Usbekistan ausgewiesen, langfristig ein- und ausreisende Usbeken wurden } \\
\text { speziell registriert und in Gesprächen überprüft. }\end{array}$ \\
\hline 23.3 .2016 & AI startet im Internet eine Unterschriftenkampagne gegen Folter in Usbekistan. \\
\hline 24.3.2016 & $\begin{array}{l}\text { Nach Angaben des staatlichen Komitees für Statistik lag die Arbeitslosenquote } 2015 \text { bei ca. } 5 \% \text { (709.400). } \\
\text { Beobachter weisen allerdings darauf hin, dass } 10-15 \% \text { der arbeitsfähigen Bevölkerung als Arbeitsmigranten } \\
\text { im Ausland tätig ist. }\end{array}$ \\
\hline
\end{tabular}

Sie können die gesamte Chronik seit 2008 auch auf <http://www.laender-analysen.de/zentralasien/> unter dem Link»Chronik«lesen.

\author{
Herausgeber: Forschungsstelle Osteuropa an der Universität Bremen und Deutsche Gesellschaft für Osteuropakunde \\ Die Meinungen, die in den Zentralasien-Analysen geäußert werden, geben ausschließlich die Auffassung der Autoren wieder. \\ Abdruck und sonstige publizistische Nutzung sind nach Rücksprache mit der Redaktion gestattet. \\ Verantwortliche Redakteurin: Beate Eschment \\ Redaktionsassistenz: Henryk Alff \\ Satz: Matthias Neumann \\ Zentralasien-Analysen-Layout: Matthias Neumann, nach einen Konzept von Cengiz Kibaroglu, mit einer Grafik von Sebastian Klüsener \\ Alle Ausgaben der Zentralasien-Analysen sind mit Themen- und Autorenindex archiviert unter www.laender-analysen.de \\ Die Zentralasien-Analysen werden im Rahmen der Datenbank World Affairs Online (WAO) ausgewertet und sind im Portal IREON www.ireon-portal.de recherchierbar. \\ ISSN 1866-2110 @ 2016 by Deutsche Gesellschaft für Osteuropakunde e.V. und Forschungsstelle Osteuropa, Bremen \\ e-mail:Zentralasien-Analysen@dgo-online.org•Internet-Adresse: www.laender-analysen.de/zentralasien
}




\section{Kostenlose E-Mail-Dienste der Forschungsstelle Osteuropa und ihrer Partner auf www.laender-analysen.de}

Die Länder-Analysen bieten regelmäßig im kostenlosen Abonnement kompetente Einschätzungen aktueller politischer, wirtschaftlicher, sozialer und kultureller Entwicklungen in Ostmitteleuropa und der GUS. Sie machen das Wissen, über das die wissenschaftliche Forschung in reichem Maße verfügt, für Politik, Wirtschaft, Medien und die interessierte Öffentlichkeit verfügbar. Autoren sind internationale Fachwissenschaftler und Experten.

Die einzelnen Länder-Analysen werden von der Forschungsstelle Osteuropa an der Universität Bremen und der Deutschen Gesellschaft für Osteuropakunde jeweils mit unterschiedlichen Partnern und Sponsoren herausgegeben. Die Redaktionen der Länder-Analysen bestehen aus Wissenschaftlern mit langjähriger Forschungserfahrung.

Die Länder-Analysen bieten regelmäßig Kurzanalysen zu aktuellen Themen, ergänzt um Grafiken und Tabellen sowie Dokumentationen. Zusätzlich gibt es eine Chronik aktueller Ereignisse. Alle Länder-Analysen sind auch mit Archiv und Indizes online verfügbar unter $<$ www.laender-analysen.de $>$.

\section{Belarus-Analysen}

Erscheinungsweise: zweimonatlich

Abonnement unter: <http://www.laender-analysen.de/belarus/>

\section{Caucasus Analytical Digest}

In englischer Sprache. Erscheinungsweise: monatlich

Abonnement unter: <http://www.css.ethz.ch/en/publications/cad.html>

\section{Polen-Analysen}

Erscheinungsweise: zweimal monatlich

Abonnement unter: <http://www.deutsches-polen-institut.de/newsletter/polen-analysen/>

\section{Russland-Analysen}

Erscheinungsweise: zweiwöchentlich

Abonnement unter: <http://www.laender-analysen.de/russland/>

\section{Russian Analytical Digest}

In englischer Sprache. Erscheinungsweise: zweimal monatlich

Abonnement unter: <http://www.css.ethz.ch/en/publications/rad.html>

\section{Ukraine-Analysen}

Erscheinungsweise: zweimal monatlich

Abonnement unter: <http://www.laender-analysen.de/ukraine/>

\section{Zentralasien-Analysen}

Erscheinungsweise: monatlich

Abonnement unter: <http://www.laender-analysen.de/zentralasien/>

\section{Bibliographische Dienste}

Die Bibliographien informieren über englisch- und deutschsprachige Neuerscheinungen zu Belarus, Russland, Ukraine sowie zu den zentralasiatischen und kaukasischen Staaten. Erfasst werden jeweils die Themenbereiche Politik, Außenpolitik, Wirtschaft und Soziales.

Erscheinungsweise: viermal jährlich

Abonnement unter: <http://www.laender-analysen.de/bibliographies/belarus.php $>$, <http://www.laender-analysen. de/bibliographies/russia.php>, <http://www.laender-analysen.de/bibliographies/ukraine.php>, <http://www.laenderanalysen.de/bibliographies/caucasus_ca.php> 